\title{
XPS Determination of Mn Oxidation States in Mn (Hydr)oxides
}

Eugene S. Ilton ${ }^{1}$, Jeffrey E. Post ${ }^{2}$, Peter J. Heaney ${ }^{3}$, Florence T. Ling ${ }^{3}$, Sebastien N. Kerisit $^{1}$

${ }^{1}$ Pacific Northwest National Laboratory, 902 Battelle Blvd, Richland WA, 99352

${ }^{2}$ Smithsonian Institution, Dept. of Mineral Sciences, NHB 119, PO Box 37012, Washington DC 20013-7012

${ }^{3}$ Dept. of Geosciences, Pennsylvania State University, University Park, PA 16802

Keywords:

XPS; manganese; valence; birnessite; catalysis; oxidation. 


\section{ABSTRACT}

Hydrous manganese oxides are an important class of minerals that help regulate the geochemical redox cycle in near-surface environments and are also considered to be promising catalysts for energy applications such as the oxidation of water. A complete characterization of these minerals is required to better understand their catalytic and redox activity. In this contribution an empirical methodology using X-ray photoelectron spectroscopy (XPS) is developed to quantify the oxidation state of hydrous multivalent manganese oxides with an emphasis on birnessite, a common layered structure that occurs commonly in soils but is also the oxidized endmember in biomimetic water-oxidation catalysts. The $\mathrm{Mn} 2 p_{3 / 2}, \mathrm{Mn} 3 p$, and $\mathrm{Mn} 3 s$ lines of near monovalent $\mathrm{Mn}(\mathrm{II}), \mathrm{Mn}(\mathrm{III})$, and $\mathrm{Mn}(\mathrm{IV})$ oxides were fit with component peaks; after the best fit was obtained the relative widths, heights and binding energies of the components were fixed. Unknown multivalent samples were fit such that binding energies, intensities, and peak-widths of each oxidation state, composed of a packet of correlated component peaks, were allowed to vary. Peak-widths were constrained to maintain the difference between the standards. Both average and individual mole fraction oxidation states for all three energy levels were strongly correlated, with close agreement between $\mathrm{Mn} 3 s$ and $\mathrm{Mn} 3 p$ analyses, whereas calculations based on the $\mathrm{Mn} 2 p_{3 / 2}$ spectra gave systematically more reduced results. Limited stoichiometric analyses were consistent with Mn3p and Mn3s. Further, evidence indicates the shape of the Mn3p line was less sensitive to the bonding environment than that for $\mathrm{Mn} 2 p$. Consequently, fitting the $\mathrm{Mn} 3 p$ and Mn3s lines yielded robust quantification of oxidation states over a range of Mn (hydr)oxide phases. In contrast, a common method for determining oxidation states that utilizes the multiplet splitting of the Mn3s line was found to be not appropriate for birnessites. 


\section{Introduction}

Manganese $(\mathrm{Mn})$ oxides occur in a wide variety of soil environments, typically as trace minerals that coat grain surfaces or as fine-grained concretions and nodules [1]. Even when the abundance of Mn oxides is on the order of a few weight percent or less, these phases can exert the primary control on cation exchange [2-6] and on redox activity [7; 8]. Mn is known to adopt ten distinct oxidation states $(7+$ through $3-)$, but in naturally occurring minerals only three oxidation states $(2+, 3+$, and $4+)$ are observed [1]. Mn oxides are the only minerals that are sufficiently oxidative to transform $\mathrm{Cr}^{3+}$ to $\mathrm{Cr}^{6+}$ [9], and, not surprisingly, the redox activity of a given Mn (hydr)oxide is closely tied to its average Mn oxidation state. Efforts to tease out the relation between valence state and $\mathrm{Cr}^{3+}$ oxidation efficiency have targeted the wide range of valence states observed in Mn (hydr)oxides, including:

- monovalent $\mathrm{Mn}(\mathrm{IV})$ oxides, such as pyrolusite $\left[\mathrm{Mn}^{4+} \mathrm{O}_{2}\right][10-12]$;

- monovalent $\mathrm{Mn}(\mathrm{III})$ oxides, such as manganite $\left[\mathrm{Mn}^{3+} \mathrm{OOH}\right]$ [12] and synthetic $\mathrm{Mn}^{3+}{ }_{2} \mathrm{O}_{3}[13]$

- mixed (MnIII/IV) hydroxides, such as romanechite $\left[\mathrm{Ba}_{\mathrm{x}} \mathrm{Mn}^{3+}{ }_{2 \mathrm{x}} \mathrm{Mn}^{4+}{ }_{1-2 \mathrm{x}} \mathrm{O}_{2} \cdot 2 \mathrm{H}_{2} \mathrm{O}\right]$, todorokite $\quad\left[(\mathrm{Ca}, \mathrm{Na}, \mathrm{K})_{\mathrm{x}}\left(\mathrm{Mn}^{4+}, \mathrm{Mn}^{3+}\right)_{6} \mathrm{O}_{12} \cdot 3.5 \mathrm{H}_{2} \mathrm{O}\right], \quad$ cryptomelane $\left[\mathrm{K}_{\mathrm{x}}\left(\mathrm{Mn}^{4+}, \mathrm{Mn}^{3+}\right)_{8} \mathrm{O}_{16}\right]$, and lithiophorite $\left[\mathrm{LiAl}_{2}\left(\mathrm{Mn}^{4+}{ }_{2} \mathrm{Mn}^{3+}\right) \mathrm{O}_{6}(\mathrm{OH})_{6}[12]\right.$

- mixed (MnII/III) oxides, such as hausmannite $\left[\mathrm{Mn}^{3+}\left(\mathrm{Mn}^{2+}, \mathrm{Mn}^{3+}\right)_{2} \mathrm{O}_{4}\right][9 ; 12 ; 14]$; and

- mixed (MnII/III/IV) oxides, such as birnessite [9;12;14-21].

Comparative investigations reveal that of all $\mathrm{Mn}$ oxide phases, birnessite oxidizes $\mathrm{Cr}^{3+}$ to $\mathrm{Cr}^{6+}$ most rapidly [9;12], but the relationship between $\mathrm{Mn}$ oxidation state and the oxidative potential of the mineral is particularly problematic with respect to birnessite. Birnessite can 
exhibit either hexagonal $\left[\mathrm{Mn}^{2+}{ }_{0.05} \mathrm{Mn}^{3+}{ }_{0.12}\left(\mathrm{Mn}^{4+}{ }_{0.74} \mathrm{Mn}^{3+}{ }_{0.10} \square_{0.17}\right) \mathrm{O}_{1.7}(\mathrm{OH})_{0.3}\right]$ or triclinic $\left[\mathrm{Na}_{0.58}\left(\mathrm{Mn}^{4+}{ }_{1.42} \mathrm{Mn}^{3+}{ }_{0.58}\right) \mathrm{O}_{4} \cdot 1.5 \mathrm{H}_{2} \mathrm{O}\right]$ symmetries [22-26], and as indicated by the proposed formulas of these idealized endmembers, the variants of birnessite contain different relative concentrations of $\mathrm{Mn}^{2+}, \mathrm{Mn}^{3+}$, and $\mathrm{Mn}^{4+}$. The degree of variation in $\mathrm{Mn}^{2+}: \mathrm{Mn}^{3+}: \mathrm{Mn}^{4+}$ ratios that are observed, or are even structurally allowable, among either hexagonal birnessites or triclinic birnessites, and their relationship to the redox potential is under constrained.

Such concerns are also manifest in the green energy community where, for example, birnessite is a primary phase in biomimetic water-oxidation catalysts [27-31]. In order to understand the efficiency of water oxidation by Mn (hydr)oxide phases and the electronic state of the Mn cations in those phases, it is critically important to know the concentrations of $\mathrm{Mn}(\mathrm{II})$, $\mathrm{Mn}(\mathrm{III})$, and $\mathrm{Mn}(\mathrm{IV})$ [32].

Mn K- and L-edge XANES have been used to measure the average oxidation state of Mn by modeling the edge position and the mole fractions of Mn oxidations states by modeling peak shapes, including pre-edge features [33-36]. Nonetheless, XANES is a bulk technique and the near-surface chemistry of the material may be of greater significance as this is where reactions are mediated. Similarly, surface-sensitive information is required to determine the nature and oxidation state of Mn precipitates that form and can undergo redox reactions at mineral surfaces, an important part of the Mn redox cycle in the environment $[37 ; 38]$.

X-ray photoelectron spectroscopy (XPS) is a non-destructive in-house method that has been used since the early 1970s to determine the oxidation states of metals, including manganese, at the near-surface of materials. A common approach takes advantage of the sensitivity of the binding energy (BE) of various electron energy levels (i.e., $\mathrm{Mn} 2 p, \mathrm{Mn} 3 p$, and $\mathrm{Mn} 3 s$ ) to the $\mathrm{Mn}$ valence state. This technique can provide an assessment of average Mn oxidation states (e.g., 
[37]) assuming samples are compared on the same energy scale, not necessarily a trivial task for insulators. Further, it is well known that changes in bonding environment (e.g., variations in ionicity/covalency and the Madelung potential) can affect BEs given the same formal oxidation state. Coupling the Auger parameter to BE can help further distinguish Mn oxidation states [39].

Much work has focused on correlating the multiplet splitting (MS) in the Mn3s line to monovalent $\mathrm{Mn}$ oxides such as $\mathrm{MnO}, \mathrm{Mn}_{2} \mathrm{O}_{3}, \mathrm{MnOOH}$ and $\mathrm{MnO}_{2}$, where the $\mathrm{MS}$ is defined as the energy difference between two prominent peaks that comprise the XPS spectrum; for a compilation of early work see Junta and Hochella [38]. The relevant atomic physics that produces the Mn3s MS has been discussed in many previous publications; see for example [4043]. Typically the relationship for simple oxides is linear, with some studies demonstrating that the MS for the doubly valent (II and III) oxide $\mathrm{Mn}_{3} \mathrm{O}_{4}$ correctly predicts its oxidation state to be 2.67+; e.g., Galakhov et al. [44]. This linear relationship for doubly valent compounds is expected on the basis of simple theoretical arguments, as long as the electronegativity of the ligands is similar; for a recent paper see Kosakov et al. [45]. In fact, deviations from linearity have been attributed to certain electronic states [44]. In this regard, it is helpful to note that the Mn3s MS for $\mathrm{Mn}_{2} \mathrm{O}_{3}$ and $\mathrm{MnOOH}$ are within error of each other. Obviously, if Mn exhibits three valence states the MS method can at best yield only average oxidation states; it is not clear, however, whether a linear relationship is to be expected.

In only a few cases, Mn3s spectra were fit using Mn(II), Mn(III), and Mn(IV) standards to determine the percentage of each oxidation state in potential multivalent aqueous precipitates [46] and synthetic Mn oxides [47]. A number of studies modeled $M n 2 p$ [45; 47-51] and Mn3p spectra $[52 ; 53]$. The papers by co-authors Nesbitt and Banjeree [48-50] are particularly relevant here as they characterized the oxidation state of multivalent K-birnessites. These studies were 
ambitious because they adapted the atomic multiplet models of Gupta and Sen [54;55] for characterizing the shapes of the $\mathrm{Mn}(\mathrm{II}), \mathrm{Mn}(\mathrm{III})$, and $\mathrm{Mn}(\mathrm{IV}) 2 p_{3 / 2}$ spectral components. Recently, the $\mathrm{Mn} 2 p_{3 / 2}$ fit parameters from Nesbitt and Banjeree were applied to K-birnessites in a water oxidation catalyst study [32]. The work by Cerrato et al. [52;53] is notable for using the binding energies and shapes of the Mn3p lines, along with the Mn3s MS to assess the oxidation state of low concentrations of $\mathrm{Mn}$ trapped on water filtration media. It is all the more remarkable given that $\mathrm{Mn} 3 s$ and $3 p$ energy levels have low photoionization cross-sections (i.e., low sensitivities).

Despite the technological and environmental importance of layered Mn (hydr)oxides, such as birnessites, and all the structural determinations [22-26], there have been few systematic efforts to determine relative $\mathrm{Mn}(\mathrm{II}), \mathrm{Mn}(\mathrm{III})$, and $\mathrm{Mn}(\mathrm{IV})$ concentrations in these multivalent compounds. This knowledge is necessary for a full description of these minerals as well as an understanding of their reactivities. An exception is the work cited above on K-birnessites; however, the XPS characterization of oxidation states was limited to modeling the $\mathrm{Mn} 2 p_{3 / 2}$ spectrum. In this contribution we present a systematic study comparing and contrasting $\mathrm{Mn}$ oxidation states determined by modeling the $\mathrm{Mn} 2 p_{3 / 2}, \mathrm{Mn} 3 p$, and $\mathrm{Mn} 3 s$ lines for a broad range of birnessite phases. Additionally, we rigorously tested the efficacy of using the Mn3s MS for predicting the average oxidation state of these multivalent Mn (hydr)oxides. Our objective is to develop a purely empirical methodology that is nevertheless robust and easy to implement.

\section{Experimental}

Near monovalent natural and synthetic minerals were used as standards: $\mathrm{MnO}$ (single crystal cleaved in vacuum; data courtesy of L. Sangeletti [42]), $\mathrm{MnCO}_{3}$ (natural crystals of 
rhodocrosite from Aldama, Sonora, Mexico and reagent grade powder; no difference detected in Mn peak shapes), $\mathrm{MnOOH}$ (manganite; Smithsonian Institution $\# \mathrm{NMNH}$ 157872), $\mathrm{MnO}_{2}$ (pyrolusite and rancieite; Smithsonian Institution \#NMNH 11478546 and \#NMNH 160078, respectively).

Triclinic Na-birnessite was synthesized according to the procedure described in Golden et al. [56]. A $200 \mathrm{ml}$ solution of $0.5 \mathrm{M} \mathrm{MnCl}_{2}$ (Mallinckrodt Baker) was mixed with $250 \mathrm{ml}$ of 5.5 $M \mathrm{NaOH}$ (J.T. Baker). The mixture was oxygenated through a glass frit for $\sim 5$ hrs at a rate of 1.5 $\mathrm{L} / \mathrm{min}$. The precipitate was divided evenly and centrifuged in 14 centrifuge tubes. The solution was decanted and replaced with fresh deionized (DI) water to rinse. The rinse cycle was repeated five times. Na-birnessite was stored in $\sim 350 \mathrm{ml}$ DI water until experimental use. For experiments, aliquots of Na-birnessite were filtered with a $70 \mathrm{~mm}$, ashless, Grade 40 filter (Whatman), rinsed three times with $100 \mathrm{~mL}$ DI water, and left to air-dry. The Na-birnessite was then ground in an agate mortar under acetone to disaggregate clumps. The synthesis of triclinic Na-birnessite with $<1$ wt $\%$ hausmannite was confirmed with a Rigaku II D/MAX-RAPID microdiffractometer (Department of Mineral Sciences, Smithsonian Institution) with a Mo tube source $(\lambda=0.7093 \AA)$.

Triclinic K-, Ca-, and Ba-birnessites were created by exchanging interlayer $\mathrm{Na}$ in triclinic Na-birnessite with $\mathrm{K}, \mathrm{Ca}$, and Ba. A $0.1 M \mathrm{KCl}$ solution was prepared with $1.4951 \mathrm{~g} \mathrm{KCl}$ (Fluka) diluted to $200 \mathrm{ml}$. A $0.01 \mathrm{M} \mathrm{CaCl}_{2}$ solution was made from $0.3932 \mathrm{~g} \mathrm{CaCl}_{2} \cdot 2 \mathrm{H}_{2} \mathrm{O}$ (Amresco) diluted to $250 \mathrm{ml}$ with DI water. A $0.1 \mathrm{M} \mathrm{BaCl}_{2}$ solution was mixed using $4.1718 \mathrm{~g} \mathrm{BaCl}_{2}$ (J.T. Baker) in $200 \mathrm{ml}$ DI water. All solutions were adjusted to $\mathrm{pH} 7$ using $0.1 \mathrm{M} \mathrm{HCl}$ (OmniTrace) and $0.1 M \mathrm{NaOH}$ (J.T. Baker). For each, $\sim 70$ to $100 \mathrm{mg}$ of triclinic Na-birnessite was placed in a $250 \mathrm{ml}$ glass beaker with $100 \mathrm{ml}$ of $0.1 \mathrm{M} \mathrm{KCl}, \mathrm{CaCl}_{2}$, or $\mathrm{BaCl}_{2}$ solution for $\sim 24 \mathrm{hrs}$. Each 
sample was confirmed with XRD and analyzed on a FEI Nova NanoSEM 600 (15 keV, 1 - 2 nA) equipped with a ThermoFisher energy dispersive spectroscopy X-ray detector (EDS) (Department of Mineral Sciences, Smithsonian Institution) to check for cation exchange.

A pH 2 hexagonal H-birnessite was synthesized by reacting $\sim 100 \mathrm{mg}$ of dried triclinic Nabirnessite in $250 \mathrm{ml}$ of $0.01 \mathrm{MHNO}_{3}$ (Trace metal grade, Fisher Scientific) for $24 \mathrm{hrs}$. It was then filtered, rinsed three times with $100 \mathrm{~mL} \mathrm{DI}$ water, and left to air-dry. For the $\mathrm{pH} 7$ hexagonal H-birnessite, a $20 \mathrm{mM}$ HEPES solution was prepared by dissolving 2.38 g HEPES (Sigma-Aldrich) into $\sim 300 \mathrm{ml}$ DI water. The $\mathrm{pH}$ was then adjusted with $0.1 \mathrm{M} \mathrm{NaOH}$ (J.T. Baker) until $\mathrm{pH} 7.00$ was achieved, and the volume was brought up to $500 \mathrm{~mL}$. About $100 \mathrm{mg}$ of triclinic Na-birnessite was reacted with $250 \mathrm{ml}$ of the pH $720 \mathrm{mM}$ HEPES solution to yield the pH 7 hexagonal H-birnessite. Both hexagonal birnessites were characterized by XRD.

Samples in the form of powder were pressed with clean borosilicate glass blocks onto copper stubs that were covered with a strip of conductive copper tape. All preparation occurred under atmospheric conditions. XPS measurements were performed with a Kratos Axis Ultra DLD spectrometer that employs a monochromatic Al $K \alpha$ X-ray $(1486.7 \mathrm{eV})$ source operating at $10 \mathrm{~mA}$ and $15 \mathrm{kV}$. Collection efficiency was enhanced by use of a magnetic immersion lens. The instrument work function was calibrated to give a $\mathrm{BE}$ of $83.96 \mathrm{eV} \pm 0.05 \mathrm{eV}$ for the $4 f_{7 / 2}$ line of metallic gold and the spectrometer dispersion was adjusted to give a BE of $932.62 \mathrm{eV}$ for the $\mathrm{Cu} 2 p_{3 / 2}$ line of metallic copper. High resolution measurements of $\mathrm{Mn} 2 p, \mathrm{Mn} 3 s, \mathrm{Mn} 3 p, \mathrm{O} 1 s$, $\mathrm{C} 1 s$, and various alkali and alkaline Earth lines were performed with an analysis area of $300 \mathrm{x}$ 700 microns, a step size of $0.1 \mathrm{eV}$, and pass energies (PE) of 20 or $40 \mathrm{eV}$ which produced a fullwidth-at-half- maximum (FWHM) for the $\mathrm{Ag} 3 d_{5 / 2}$ line of 0.54 and $0.77 \mathrm{eV}$, respectively. Due to 
the low sensitivity of the Mn3s line, it was only measured with $\mathrm{PE}=40 \mathrm{eV}$. Survey scans were performed at $\mathrm{PE}=160 \mathrm{eV}$ and step size $=0.5 \mathrm{eV}$.

Spectra were best fit, after Shirley background subtractions, by non-linear least squares using the CasaXPS curve resolution software package. Gaussian/Lorentzian $(\mathrm{G} / \mathrm{L})$ contributions to the line shapes were numerically convoluted using a Voigt function. A more rigorous approach would be to fix the Lorentzian FWHM to a value based on the core-hole lifetime but allow the Gaussian aspect to vary independently to compensate for instrument and charge induced broadening. Nonetheless, the present approach is sufficient for the task at hand, given that CasaXPS is widely used and that the fit parameters are only intended for a limited compositional/structural range of Mn minerals (i.e., Mn (hydr)oxides). Instrument-specific sensitivity factors were used for quantification.

\section{Results and discussion}

In order to develop a reproducible methodology for extracting the relative concentrations of $\mathrm{Mn}^{2+}, \mathrm{Mn}^{3+}$, and $\mathrm{Mn}^{4+}$ from multivalent $\mathrm{Mn}$ (hydr)oxides, we adopted a multistep strategy. First, we extracted fit parameters from monovalent $\mathrm{Mn}(\mathrm{II}), \mathrm{Mn}(\mathrm{III})$, and $\mathrm{Mn}(\mathrm{IV})$ standards for the $\operatorname{Mn} 2 p_{3 / 2}, \operatorname{Mn} 3 p$, and Mn3s spectra. Next, we used the fit parameters to determine the oxidation states of $\mathrm{Mn}$ in the doubly valent minerals hausmannite $\left(\mathrm{Mn}^{2+} \mathrm{Mn}^{3+}{ }_{2} \mathrm{O}_{4}\right)$ and romanechite $\left(\mathrm{Ba}_{\mathrm{x}} \mathrm{Mn}^{3+}{ }_{2 \mathrm{x}} \mathrm{Mn}^{4+}{ }_{1-2 \mathrm{x}} \mathrm{O}_{2} \cdot 2 \mathrm{H}_{2} \mathrm{O}\right)$. An attempt to use the entire $\mathrm{Mn} 2 p$ spectrum, as opposed to just $\mathrm{Mn} 2 p_{3 / 2}$, was abandoned because of inconsistent results possibly due to mixed valence effects in the satellite region. Then, we analyzed a class of manganese (hydr)oxides (birnessites) that can contain $\mathrm{Mn}$ in any of three oxidation states. The stoichiometries of selected samples were determined and compared to the fitting results. Finally, synthetic Mn3s spectra were generated to 
test how well the Mn3s multiplet splitting (MS) is correlated to the oxidation state of Mn in birnessites.

\subsection{Standards}

An empirical method was used to extract oxidation state information for Mn by fitting the different XPS Mn lines with sets of Gaussian/Lorentzian peaks derived from our standards. This approach is similar to that of Nesbitt and Banerjee [48] and Biesinger et al. [57]; however, unlike those two studies, which focused solely on the $\mathrm{Mn} 2 p_{3 / 2}$ line, we were not guided by the atomic multiplet models of Gupta and Sen $[54 ; 55]$. Instead, here we were simply attempting to achieve the best empirical fit to the spectra and any similarity between the spacing and relative intensities of component peaks and atomic multiplet models should be viewed as serendipitous.

A single crystal of $\mathrm{MnO}$ served as a standard for $\mathrm{Mn}(\mathrm{II})$ where the XPS data were generated in a previous study [42] (see Experimental). Theory and experiment showed good agreement for major features [58]; in particular, neither showed any asymmetry or shoulder on the low BE side of the $\mathrm{Mn} 2 p_{3 / 2}$ line, in contrast to the data in Biesinger et al. [57]. We have noticed such an asymmetry or shoulder in spectra from natural $\mathrm{MnO}$ samples (accompanied by diminished satellite intensity) that appear to be partially hydrated, as determined by XPS, and speculate that two Mn species may be present. Fit parameters for Mn2 $p_{3 / 2}, \operatorname{Mn} 3 s$ and Mn3p spectra along with the Mn3s MS, are given in Table 1 and shown in Figure 1.

Ideally, we would have collected data from a $\mathrm{Mn}(\mathrm{OH})_{2}$ standard to test the effect of increasing hydroxylation and ionicity. Unfortunately, highly crystalline natural samples appear to be rare perhaps due to high reactivity towards oxidation and presence of impurities. Instead, we analyzed natural and reagent $\mathrm{MnCO}_{3}$ which is more ionic than $\mathrm{MnO}$. Stoichiometries for both 
samples as determined by XPS indicate a near 1:1 ratio of $\mathrm{Mn}$ to $\mathrm{CO}_{3}$ (determined using both the $\mathrm{C} 1 s$ and $\mathrm{O} 1 s$ lines). A comparison of the spectra for the three different Mn energy levels for $\mathrm{MnCO}_{3}$ and $\mathrm{MnO}$ show similarities and differences (Figure 2). The $\mathrm{Mn} 3 p$ spectra for $\mathrm{MnO}$ and $\mathrm{MnCO}_{3}$ are similar, whereas significant differences are apparent for the $\mathrm{Mn} 2 p$ spectra in the region between the spin-orbit split primary peaks. Consequently, we suspect that the bonding environment will more strongly affect the $\mathrm{Mn}(\mathrm{II})$ component in the $\mathrm{Mn} 2 p_{3 / 2}$ peak compared to $\mathrm{Mn}(\mathrm{II})$ in $\mathrm{Mn} 3 p$. As expected, the $\mathrm{MS}$ for $\mathrm{MnCO}_{3}(6.2 \mathrm{eV})$ is slightly larger than that for $\mathrm{MnO}$ $(6.1 \mathrm{eV})$ due to greater ionicity. Other than that, the peak shapes are similar with only a modest difference in multiplet amplitudes (Figure 2).

The Mn(III) standard is the mineral manganite with nominal stoichiometry $\mathrm{MnOOH}$ (see Experimental); an XPS survey scan revealed little to no detectable contamination. A fit of the $\mathrm{O} l s$ line yielded stoichiometric proportions of $\mathrm{O}$ and $\mathrm{OH}$ (not shown). Empirical parameters for simulating the Mn2 $p_{3 / 2}, \mathrm{Mn} 3 s$, and $\mathrm{Mn} 3 p$ lines and the Mn3s MS are given in Table 1 and illustrated in Figure 1. The fit parameters for the $\mathrm{Mn} 2 p_{3 / 2}$ peak are different than those in Biesinger et al. [57] and Nesbitt and Banjeree [48]. Those studies were guided by an atomic multiplet model $[54 ; 55]$. As stated earlier, we are committed to a fully empirical approach.

According to Biesinger et al. [57] the $\mathrm{Mn}_{2} \mathrm{O}_{3}$ (bixbyite) and $\mathrm{MnOOH}$ (manganite) $\mathrm{Mn} 2 p_{3 / 2}$ lines have similar BE ranges and slightly different peak shapes. We used the parameters from the $\mathrm{MnOOH}$ standard to model the $\mathrm{Mn} 2 p_{3 / 2}$ spectrum from a natural bixbyite containing $\sim 10 \%$ Fe (NMNH \#151352) and obtained a poor fit to the top and high BE tail portions of the spectrum (Figure 3). In contrast, the $\mathrm{Mn} 3 p \mathrm{MnOOH}$ parameters worked well for the bixbyite Mn3p line after accounting for a slight overlap with $\mathrm{Fe} 3 p$ (Figure 3). Unfortunately, the $\mathrm{Fe} 3 s$ line strongly overlapped with the Mn3s line. Nonetheless, it has been well documented in the literature that 
the $\mathrm{Mn} 3 s \mathrm{MS}$ for $\mathrm{Mn}_{2} \mathrm{O}_{3}$ and $\mathrm{MnOOH}$ are within error of each other [38]; the Mn3s MS for $\mathrm{MnOOH}$ of $5.4 \mathrm{eV}$ obtained in this study is in agreement with published values [38]. Thus, it appears that, as observed for $\mathrm{Mn}(\mathrm{II})$, the $\mathrm{Mn}(\mathrm{III}) 3 p$ line is less affected by bonding environment than the $\mathrm{Mn}(\mathrm{III}) 2 p_{3 / 2}$ line. In fact, use of bixbyite $\mathrm{Mn} 2 p_{3 / 2}$ parameters (not shown) yielded appreciably worse fits to birnessites (not shown) than the manganite parameters and their use was discontinued.

XPS of pyrolusite $\left(\mathrm{MnO}_{2}\right)$ showed signs of minor reduction and the sample was, therefore, exposed to UV-ozone for 10 minutes. Fitting with the $\mathrm{Mn}(\mathrm{III}) 2 p_{3 / 2} \mathrm{MnOOH}$ standard parameters yielded $\sim 10 \% \mathrm{Mn}(\mathrm{III})$ (originally around $20 \%$ ). However, the derived $\mathrm{Mn}(\mathrm{IV}$ ) parameters from pyrolusite yielded poor fits to the $\mathrm{Mn} 2 p_{3 / 2}$ birnessite spectra. Consequently, we switched to a Mn(IV)-rich rancieite (see Experimental). Rancieite has a birnessite-like layer structure [59], and therefore the $\mathrm{Mn}(\mathrm{IV})$ bonding environments in the two phases are similar. $\mathrm{Mn}(\mathrm{IV}) 2 p_{3 / 2}$ fitting parameters extracted from rancieite (Table 1 and illustrated in Figure 1) greatly improved subsequent fits to the various birnessite-like samples; all $\mathrm{Mn} 2 p_{3 / 2}$ results listed and discussed in this contribution were obtained with rancieite-Mn(IV) parameters. Nesbitt and Banjeree [48] used a similar approach for curve resolution of K-birnessites: They began with pyrolusite and then modified the $\mathrm{Mn}(\mathrm{IV}) 2 p_{3 / 2}$ parameters to best fit a Mn(IV)-rich K-birnessite.

Modeling the pyrolusite Mn3p line with the Mn(III) $3 p$ standard parameters gave only 5\% $\mathrm{Mn}(\mathrm{III})$, indicating that the surface was likely marginally more reduced than the bulk (the UV ozone treatment does not penetrate far into the bulk). As will be discussed below, the $\operatorname{Mn} 2 p_{3 / 2}$ spectra originate closer to the sample surface than do those for Mn3p and Mn3s. Importantly, and in contrast to $\mathrm{Mn} 2 p_{3 / 2}$, the $\mathrm{Mn}(\mathrm{IV}) 3 p$ spectra derived from pyrolusite and rancieite were nearly identical (parameters are listed in Table 1 and shown in Figure 1). This is illustrated in 
Figure 4 (left panel) where the rancieite $\mathrm{Mn}(\mathrm{IV}) 3 p$ parameters are shown to well fit the pyrolusite $\mathrm{Mn} 3 p$ spectrum. In contrast, the rancieite $\mathrm{Mn}(\mathrm{IV}) 2 p_{3 / 2}$ parameters do not properly fit the upper portion of the pyrolusite $\mathrm{Mn} 2 p_{3 / 2}$ (Figure 4, right panel). Consequently, and similar to the cases for $\mathrm{Mn}(\mathrm{II})$ and $\mathrm{Mn}(\mathrm{III})$, the shape of the $\mathrm{Mn}(\mathrm{IV}) 3 p$ peak appears to be less susceptible to variations in $\mathrm{Mn}$ bonding environment compared to the $\mathrm{Mn}(\mathrm{IV}) 2 p_{3 / 2}$ line.

We then assumed $5 \% \mathrm{Mn}(\mathrm{III})$ in the pyrolusite $\mathrm{Mn} 3 s$ peak and attempted to extract the Mn3s Mn(IV) fitting parameters. Unfortunately, the binding energy of the Mn(III) component was not stable and slid to the low binding energy tail. Therefore, we used the UV-ozoned pyrolusite $\mathrm{Mn} 3 s$ line as is for the $\mathrm{Mn}(\mathrm{IV}) 3 s$ standard, with the understanding that it is likely $95 \%$ $\mathrm{Mn}(\mathrm{IV})$ and $5 \% \mathrm{Mn}(\mathrm{III})$. Zn interfered with the Mn3s line of rancieite, and a comparison with pyrolusite was not attempted. However, as shown later, the strong agreement between Mn3p and Mn3s for all mixed valence samples studied, suggests that pyrolusite does serve as an acceptable Mn(IV)3s standard. Fit parameters are given in Table 1 and illustrated in Figure 1.

In summary, differences in the coordination environment of $\mathrm{Mn}(\mathrm{II})$ in $\mathrm{MnO}$ and $\mathrm{MnCO}_{3}$ only slightly perturb the shape of the Mn3p lines, but appreciably affect $\mathrm{Mn} 2 p_{3 / 2}$. Comparison of XPS spectra for $\mathrm{Mn}_{2} \mathrm{O}_{3}$ and $\mathrm{MnOOH}$ indicate that their $\mathrm{Mn}(\mathrm{III}) 3 p$ line shapes are nearly identical, whereas the $\mathrm{Mn} 2 p_{3 / 2}$ lines are significantly different. Likewise, the Mn(IV) $3 p$ line shapes for Mn(IV)-rich pyrolusite and rancieite are nearly indistinguishable, in contrast to the $\mathrm{Mn}(\mathrm{IV}) 2 p_{3 / 2}$ peaks. Consequently, our results suggest that the Mn $3 p$ parameters are relatively unchanged over a broader range of bonding environments than are the $\mathrm{Mn} 2 p_{3 / 2}$ parameters. Additionally, as will be shown below, given the similar information depths for Mn3p and $\operatorname{Mn} 3 s$ spectral data, consistency of results from fitting these two lines validates the use of the Mn $3 s$ spectra for Mn oxidation state analyses. 


\subsection{Curve resolution strategy}

When fitting multivalent samples, the $\mathrm{Mn}(\mathrm{II}), \mathrm{Mn}(\mathrm{III})$, and $\mathrm{Mn}(\mathrm{IV})$ fit parameters listed in Table 1 were fixed for individual oxidation states but allowed to shift energies and intensities as packets relative to other oxidation states. An allowance for relative BE shifts acknowledges the possibility that the iconicity/covalency and Madelung potential are different in multivalent compared to monovalent minerals, or in different structures. Initially the FWHM of each oxidation state was not constrained. Subsequently, the differences in FWHM between the oxidation states were fixed to those between the standards. This additional constraint improved the consistency among results determined using the $\mathrm{Mn} 3 s, \mathrm{Mn} 3 p$, and $\mathrm{Mn} 2 p_{3 / 2}$ lines, as well as the agreement between results for $\mathrm{Mn} 3 s$ and $3 p$ data. Without this constraint, BEs for $\mathrm{Mn}$ (III) and $\mathrm{Mn}$ (II) sometimes assumed nonsensical values as peak widths for one oxidation state would become unreasonably fat or narrow for no apparent physical reason. The remaining degrees of freedom allowed for fitting the FWHMs constitutes an attempt, albeit a crude one, to account for the effect of bonding environment on the MS. For example, it is well known that MS is dependent on the degree of covalency [60], where increasing covalency increases screening and decreases the exchange interaction between the core hole and unpaired valence electrons which, in turn, diminishes the MS. Another potential complication is that variations in the ligand field splitting, either due to changes in coordination symmetry or covalency, can alter the number of non-degenerate final states.

In summary, other than as described above, our approach does not directly take into account the potential effect of differences in bonding environments between the standards and samples of interest. To explicitly do so would be a complex task that might eventually be addressed with 
advanced theoretical methods or additional experience with numerous samples. Nonetheless, as discussed above, the peak shapes for $\mathrm{Mn} 3 p$ are insensitive to changes in Mn bonding environments. For our analyses of "unknown" samples, checks and balances were employed. Where possible, the stoichiometry was used to estimate the average oxidation state of Mn, which was compared to the fitting results. Additionally, comparing and contrasting independent fits to spectra for the three different Mn energy levels provided a check on the accuracy and precision of the method.

\subsection{Doubly valent samples}

We fit two minerals that nominally have $\mathrm{Mn}$ in two oxidation states; hausmannite $\left(\mathrm{Mn}^{2+} \mathrm{Mn}^{3+}{ }_{2} \mathrm{O}_{4}\right)$ and romanechite $\left(\mathrm{Ba}_{\mathrm{x}} \mathrm{Mn}^{3+}{ }_{2 \mathrm{x}} \mathrm{Mn}^{4+}{ }_{1-2 \mathrm{x}} \mathrm{O}_{2} \cdot 2 \mathrm{H}_{2} \mathrm{O}\right)$. The hausmannite specimen (Smithsonian \#NMNH 114695) is from a natural sample with detectable $\mathrm{Si}, \mathrm{Co}, \mathrm{Na}, \mathrm{Mg}$, and $\mathrm{Ca}$ as determined by XPS. It has the spinel structure with $\mathrm{Mn}(\mathrm{II})$ in tetrahedral and $\mathrm{Mn}$ (III) in octahedral coordination. The best fit to the hausmannite Mn3p spectrum yielded 10.2\% Mn(IV), $59.0 \% \mathrm{Mn}(\mathrm{III})$, and $30.7 \% \mathrm{Mn}$ (II) (Figure 5). The concentration of Mn(IV) is low but does improve the fit significantly, perhaps suggesting the presence of a secondary Mn phase. Regardless, the normalized mole fractions for $\mathrm{Mn}(\mathrm{III})$ and $\mathrm{Mn}(\mathrm{II})$ are $65.7 \%$ and $34.2 \%$, respectively, yielding an average oxidation state $2.65+$ that is nearly identical to the ideal value of $2.67+$ (and a $\mathrm{Mn}(\mathrm{II}) / \mathrm{Mn}$ (III) ratio of 1.92 , compared to the ideal value of 2.0). Fitting the $\mathrm{Mn} 2 p_{3 / 2}$ spectra was complicated by the need to accommodate the intense $\mathrm{Mn}(\mathrm{II})$ satellite which was likely buried between the two spin orbit split peaks (see Figure 2, middle panel). By varying the height of the high energy background we converged on a best fit that yielded $1.8 \% \mathrm{Mn}(\mathrm{IV})$, $65.5 \% \mathrm{Mn}(\mathrm{III})$, and $32.7 \% \mathrm{Mn}(\mathrm{II})$ (Figure 5, top panel). A similar approach was used by 
Biesinger et al. [57; 61] for modeling the $2 \mathrm{p}_{3 / 2}$ line of $\mathrm{Ni}$ compounds. Ignoring the minor $\mathrm{Mn}$ (IV) component, the results yielded normalized mole fractions of $66.7 \% \mathrm{Mn}$ (III) and $33.3 \% \mathrm{Mn}$ (II), which are remarkably close to the ideal stoichiometry for $\mathrm{Mn}_{3} \mathrm{O}_{4}$. Unfortunately, $\mathrm{Mg}$ interfered strongly with the $\mathrm{Mn} 3 s$ line.

Fitting the Mn3p spectrum of romanechite (NMNH \#C1818: nominally $\left.\mathrm{Ba}_{.66} \mathrm{Mn}(\mathrm{IV})_{3.68} \mathrm{Mn}(\mathrm{III})_{1.32} \mathrm{O}_{10} \cdot 1.34 \mathrm{H}_{2} \mathrm{O}\right)$ gives $65.5 \% \mathrm{Mn}(\mathrm{IV})$ and $34.5 \% \mathrm{Mn}(\mathrm{III})$ with no detectable $\mathrm{Mn}(\mathrm{II})$ for an average oxidation state of $3.66+$ (not shown). The romanechite structure is constructed of double and triple chains of edge-sharing Mn-O octahedra that share corners to form tunnels with a rectangular cross-section that measure 2 and 3 octahedra on a side, respectively. The tunnels are filled primarily by $\mathrm{Ba}$ (with minor $\mathrm{Ca}$ ) cations and water molecules, and the tunnel cation charges are offset by substitution of $\mathrm{Mn}$ (IV) by $\mathrm{Mn}$ (III) or other lower valence cations [62]. XPS detected both $\mathrm{Ca}$ and $\mathrm{Ba}$, and if we assume that each $\mathrm{Ca}^{2+}$ and $\mathrm{Ba}^{2+}$ measured by XPS charge balances two Mn(III), then our analysis yields $68.6 \% \mathrm{Mn}(\mathrm{IV})$ and $31.4 \% \mathrm{Mn}(\mathrm{III})$ for an average oxidation state of $3.69+$, which is within error of the fitting results. Given that we used $\mathrm{Ba} 4 p$ (Ba4d overlaps $\mathrm{Mn} 3 s$ and $\mathrm{Ba} 3 d$ is at too high a $\mathrm{BE}$ for comparison with $\mathrm{Mn} 3 s$ ) and $\mathrm{Ca} 2 p$, both of which are at higher BEs than Mn3p, the tendency would be to underestimate $\mathrm{Ca}$ and $\mathrm{Ba}$ relative to $\mathrm{Mn}$, which is consistent with stoichiometry predicting a marginally higher oxidation state. The $\mathrm{O} l s$ line is complicated and is composed of six substantial peaks that we interpret as $56 \%$ oxide $(530.0 \mathrm{eV}), 14 \%$ hydroxyl $(531.2 \mathrm{eV}), 14 \% \mathrm{C}-\mathrm{O}$ species (532.1 eV), $7 \%$ chemi-sorbed $\mathrm{H}_{2} \mathrm{O}$ and/or C-O species $(533.1 \mathrm{eV})$, and $10 \%$ physi-sorbed $\mathrm{H}_{2} \mathrm{O}$ (534.0 and $534.8 \mathrm{eV}$ ). Presumably $\mathrm{O} 1 s$ associated with $\mathrm{H}_{3} \mathrm{O}^{+}$would be at even higher BEs and was not detected. It is unlikely that $\mathrm{Ca}$ and $\mathrm{Ba}$ will promote hydrolysis of $\mathrm{H}_{2} \mathrm{O}$ in the tunnels and, in fact, chemical analyses and infrared spectroscopy of other Mn oxide tunnel structures, for 
example hollandites [63], do not indicate the presence of significant hydroxyl. A detailed singlecrystal X-ray diffraction study of this same romanechite specimen did not find evidence for a significant hydroxyl cation concentration [62]. Consequently, we suggest that most of the hydroxyls/protons are at the surface, and are not part of the bulk structure. Fitting the Mn2 $2 p_{3 / 2}$ line, which is more surface sensitive than Mn3p, yields $47.7 \% \mathrm{Mn}(\mathrm{IV}), 47.1 \% \mathrm{Mn}(\mathrm{III})$, and $4.6 \%$ $\mathrm{Mn}(\mathrm{II})$. The $\mathrm{Mn}(\mathrm{II})$ is marginal, but if real, it likely is in the tunnels or at the surface and not in the octahedral framework. Greater reduction towards the surface would be consistent with a higher concentration of protons at the surface but, as discussed previously, the $\mathrm{Mn} 2 p$ line appears to be sensitive to the bonding environment which might make the results less accurate than those for $\mathrm{Mn} 3 p$.

In general, our fit parameters work well for two very different doubly valent Mn oxides. In particular, the Mn fit parameters for Mn(III) seem to perform well when paired with $\mathrm{Mn}$ (IV) or $\mathrm{Mn}(\mathrm{II})$, and the $\mathrm{Mn}(\mathrm{II})$ results appear to be insensitive, surprisingly, to tetrahedral versus octahedral coordination in oxides. However, the results for the $\mathrm{Mn} 2 p_{3 / 2}$ spectrum for hausmannite are considered provisional, despite the good result, given the adjustments made to the high energy background (Figure 5).

\subsection{Synthetic birnessite samples: Fitting the core levels}

Examples of curve resolution for $\mathrm{Mn} 3 s, \mathrm{Mn} 2 p_{3 / 2}$, and $\mathrm{Mn} 3 s$ hexagonal birnessite (pH7) spectra, using parameters for the individual oxidation states determined from standards as described above, are illustrated in Figure 6. The insets are background subtracted without the data and fit envelopes in order to better compare and contrast the component spectra for the three different oxidation states. Quantification results of all birnessite samples are summarized in 
Table 2. The XPS results show that the samples are Mn(IV)-rich, as expected, with various amounts of $\mathrm{Mn}(\mathrm{III})$ and $\mathrm{Mn}(\mathrm{II})$. Average and individual oxidation states derived from $\mathrm{Mn} 2 p_{3 / 2}$, Mn3s, and Mn3p spectral fits are plotted in Figures 7 and 8, respectively. The average oxidation states derived from the Mn3s and $\mathrm{Mn} 3 p$ spectra are positively correlated and cluster closely around the 1:1 line (Figure 7). In contrast, the average oxidation states determined from the $\operatorname{Mn} 2 p_{3 / 2}$ spectra, although strongly correlated to the $\mathrm{Mn} 3 p$ and $\mathrm{Mn} 3 s$ results, are systematically more reduced than those determined from $\mathrm{Mn} 3 s$ and $\mathrm{Mn} 3 p$ spectra. This latter observation is consistent with the results for romanechite (as well as for the pyrolusite and rancieite samples used in this study). Recalling that the Mn3s and $\mathrm{Mn} 3 p$ photoelectrons are more energetic and record signals integrated over greater information depths than for $\mathrm{Mn} 2 p$, suggests that the surface of these Mn(IV)-rich minerals tend to be more reduced than the bulk. This is plausible given that $\mathrm{Mn}(\mathrm{IV})$ is a strong oxidant and likely will be reduced when in contact with the environment. Slow beam induced reduction of $\mathrm{MnO}_{2}$ has been documented [57]. However, beam reduction was not detected in the present study; neither sequential analyses on the same spot nor the order in which the different Mn lines were analyzed significantly affected oxidation states.

Similarly, the Mn(IV), Mn(III), and Mn(II) mole fractions are in close agreement for Mn3s and Mn3p fittings whereas $\mathrm{Mn} 2 p_{3 / 2}$ spectra yield systematically lower $\mathrm{Mn}(\mathrm{IV})$ and higher $\mathrm{Mn}(\mathrm{III})$ and $\mathrm{Mn}(\mathrm{II})$ values (Figure 8). The tight correlations and strong agreement between $\mathrm{Mn} 3 s$ and $\mathrm{Mn} 3 p$ results, and the fact that measured $3 p$ and $3 s$ values compare well with known stoichiometries (see below), suggest that the results are accurate.

Although a plausible reason for $\mathrm{Mn} 2 p_{3 / 2}$-derived values being systematically more reduced than the $\mathrm{Mn} 3 p$ and $\mathrm{Mn} 3 s$ results is that the surface is more reduced, alternatively it is possible that the $\mathrm{Mn} 2 p$ results are not accurate due to bonding environment effects. In this regard, as 
discussed above, Nesbitt and Banerjee [48] derived fit parameters for the $\mathrm{Mn} 2 p_{3 / 2}$ line that were fine-tuned to K-birnessite. Perhaps not surprisingly, application of their $\mathrm{Mn} 2 p_{3 / 2}$ parameters to the present K-birnessite sample (not shown) yielded good agreement with the fit results for $\mathrm{Mn} 3 p$, in contrast to the $\mathrm{Mn} 2 p_{3 / 2}$ parameters derived here. Other than for K-birnessite, however, the agreement is poor. Further, the goodness of fit varied strongly, with better and poorer fits associated with the triclinic and hexagonal birnessites, respectively. The opposite trend was manifest using our $\mathrm{Mn} 2 p_{3 / 2}$ parameters (Table 2). Such variability indicates that the $\mathrm{Mn} 2 p_{3 / 2}$ line is difficult to model using one set of parameters. This in turn is consistent with curve resolution of the standards which indicated that the $\mathrm{Mn} 2 p$ line appears to be more sensitive to bonding environment than Mn3p. Further, angle-resolved XPS (both Mn2p and 3p) of birnessites do not indicate significant reduction with increasing sensitivity to the surface (data not shown). Although the birnessites are in powder form, they were compressed to a vitreous luster with the platelets aligned parallel to the sample stub and the carbon/manganese ratio increased systematically with decreasing emission angles. Consequently, whereas one cannot categorically dismiss the possibility that the birnessite surfaces are more reduced than the bulk, the evidence suggests that a strong redox gradient is not present which, in turn, implies that the $\mathrm{Mn} 2 p_{3 / 2}$ fits are not accurate.

\subsection{Birnessite: Stoichiometry}

A major goal of this study was to use the methods described above to determine the concentrations of $\mathrm{Mn}(\mathrm{IV}), \mathrm{Mn}(\mathrm{III})$, and $\mathrm{Mn}(\mathrm{II})$ in synthetic and natural birnessite-like phases, in order to better understand the structures and behaviors of these layered Mn (hydr)oxides. Determining the stoichiometry for a given birnessite-like phase is problematic in a number of 
ways: (1) chemical analyses, EXAFS, and other techniques can typically, at best, determine only average Mn oxidation states because the phases are commonly triply-valent [Mn(IV), Mn(III), and $\mathrm{Mn}(\mathrm{II})]$; (2) the interlayer regions can be populated by an assortment of charge compensating cations; (3) the Mn-O octahedral layers commonly contain Mn vacancies; (4) $\mathrm{Mn}(\mathrm{II})$, and in some cases $\mathrm{Mn}(\mathrm{III})$, is thought to reside in the interlayer region capping vacancies; thus what is an interlayer cation and what is associated with the octahedral structure is somewhat blurred; and (5) "interlayer" $\mathrm{Mn}(\mathrm{II})$ might promote hydrolysis of $\mathrm{H}_{2} \mathrm{O}$, particularly at higher $\mathrm{pH}$. This last point highlights the fact that XPS only sees "hydroxyls", not distinguishing whether they formed by adsorption of protons or hydrolysis of $\mathrm{H}_{2} \mathrm{O}$ and expulsion of protons with different consequences for charge balance.

Given the many complexities listed above, we first analyzed triclinic Na-birnessite [nominally $\mathrm{Na}_{58}\left(\mathrm{Mn}^{4+}{ }_{1.42} \mathrm{Mn}^{3+}{ }_{.58}\right) \mathrm{O}_{4} \cdot 1.5 \mathrm{H}_{2} \mathrm{O}$ ] because $\mathrm{Na} 2 p$ and $\mathrm{Mn} 3 p$ have nearly identical information depths, and X-ray diffraction studies and chemical analyses [22] suggest that the $\mathrm{Mn}(\mathrm{II})$ concentration is relatively low (Table 2 ) and that the $\mathrm{Mn}(\mathrm{III})$ is located only in the Mn-O octahedral layers; i.e., it does not cap vacancies. Furthermore, the synthesis was performed at alkaline $\mathrm{pH}$ which, combined with a nominal $\mathrm{pH}_{\mathrm{pzc}}$ of $\sim 2-3$ [64], plausibly permits us to ignore the potential for adsorbed protons. The stoichiometry was calculated in three different ways. First, assuming that $\mathrm{Na}$ is the only charge-compensating cation (i.e., no other cations were detected and $\mathrm{Mn}(\mathrm{II})$ is part of the octahedral sheet) yields an average oxidation state of $3.60+$ which compares closely to the Mn3p fit result of 3.57+ (Table 2). Second, ignoring Mn(II) (considering that $\mathrm{Mn}(\mathrm{II})$ is close to the detection limit) yields $3.60+$ and $3.61+$ from stoichiometry and the Mn3p fit, respectively. Third, assuming that $\mathrm{Na}$ and $\mathrm{Mn}$ (II) are both interlayer charge-compensating cations and that the vacancy concentration is equal to $\mathrm{Mn}(\mathrm{II})$ 
yields $3.64+$ for the structural units, which also compares closely to $3.61+$ from the fit. In summary, the stoichiometry and fit results are close regardless of the model used. The identity of a minor $\mathrm{O} 1 \mathrm{~s}$ component at $531.6 \mathrm{eV}$ is ambiguous as it is high for hydroxyl in $\mathrm{MnOOH}$ $(\sim 531.0 \mathrm{eV})$. The oxygen in carbonate does have an $\mathrm{O} 1 s$ peak at $\sim 531.7 \mathrm{eV}$, but the highest BE component associated with the $\mathrm{C} 1 \mathrm{~s}$ line is at $288.9 \mathrm{eV}$ which is too low for $\mathrm{MnCO}_{3}(\mathrm{C} 1 \mathrm{~s}$ at 289.6 $\mathrm{eV}$; this study). In any case, to a first approximation, the stoichiometry and Mn3p fit yield nearly identical results.

\subsection{Birnessite: Mn3s multiplet splitting (MS)}

The Mn3s MS (see Figures 1, right panels, and 2, bottom panel) is commonly used to derive the average oxidation state of $\mathrm{Mn}$, where decreasing energy separation between the ${ }^{7} \mathrm{~S}$ and ${ }^{5} \mathrm{~S}$ multiplets is correlated to increasing formal oxidation state (see Introduction). Nonetheless, it is well known that differences in covalency/ionicity for a given formal oxidation state can also influence the MS by differential screening of the exchange interaction between the core hole and unpaired valence electrons. Consequently, knowledge of the composition of the Mn compound and in particular the dominant ligand is essential for assessing the formal valence of Mn. For example, data collected for this paper indicates that the series $\mathrm{MnO}, \mathrm{Mn}_{3} \mathrm{O}_{4}$ (taken from ref [44]), $\mathrm{MnOOH}\left(\mathrm{Mn}_{2} \mathrm{O}_{3}\right)$, and $\mathrm{MnO}_{2}$ shows a strong linear correlation between their formal valence states and the Mn3s MS (Figure 9, inset top panel). This conforms to expectation from theoretical treatments [45; 65]. Likewise, Galakhov et al. [44] show a strong correlation between the formal oxidation state of manganites and simple oxides, and the Mn3s MS. A plateau in the MS between about 3.0+ and 3.3+ was attributed to hole localization on oxygen as opposed to the metal centers. 
The immediate question addressed here concerns the accuracy of the Mn3s MS approach for determining average oxidation states of $\mathrm{Mn}$ compounds that are primarily (hydr)oxides. The question comes in two parts: How reliable is interpolating between well characterized standards and does a close match to the Mn3s MS of a standard truly yield the correct average oxidation state of the sample? Given the strong linear correlation in Figure 9 (inset), it would seem that the answers are an obvious yes for both queries, if one limits the analysis to Mn (hydr)oxides; we will show, however, that even in such a constrained system, things can get complicated.

In Figure 9 (top panel), the Mn3s MS values for the birnessite samples are plotted against the average oxidation states calculated from the Mn3s fits. The solid red line marks the assumed linear relationship between the average oxidation state and the MS. Note the lack of correlation between the MS and the fit results. Furthermore, projecting the MS onto the red line in Figure 9 (top panel) indicates that the MS predicts significantly higher oxidation states than the fitting. Given the close correspondence between the fit results for Mn3s and Mn3p, we suggest that the problem is with the MS approach.

To explore this discrepancy, we used the Mn3s Mn(III) and Mn(IV) standards to create synthetic composite spectra that spanned valence states III-IV maintaining the same BE separation between $\mathrm{Mn}(\mathrm{III})$ and $\mathrm{Mn}(\mathrm{IV})$ as in the fitted Na-birnessite or hex-birn-pH7 samples (Figure 9, bottom panel). Note that in both cases a sigmoidal, not linear, relationship is manifest. In fact, using the hex-birn-pH7 BEs yields prominent plateaus from 3.0+ to $3.3+$, and between $3.6+$ and 4.0+ where the MS appears insensitive to changes in oxidation state. The reason for the sigmoidal functions becomes readily apparent when inspecting the relative BEs of the $\mathrm{Mn}$ (III) and $\mathrm{Mn}(\mathrm{IV})$ spectra. In the case of hex-birn-pH7, the ${ }^{5} \mathrm{~S}$ and ${ }^{7} \mathrm{~S}$ multiplets for $\mathrm{Mn}(\mathrm{III})$ and $\mathrm{Mn}(\mathrm{IV})$ are offset such that changes in $\mathrm{Mn}(\mathrm{III}) / \mathrm{Mn}(\mathrm{IV})$ simply broaden the peaks instead of 
changing the MS. In this case, rapid changes in MS occur when $\mathrm{Mn}(\mathrm{III}) / \mathrm{Mn}(\mathrm{IV})$ is close to unity. In contrast, the $\mathrm{Mn}(\mathrm{III})$ and $\mathrm{Mn}(\mathrm{IV}){ }^{5} \mathrm{~S}$ multiplets for Na-birn are closely overlapped whereas the ${ }^{7} \mathrm{~S}$ multiplets are offset. This increases the sensitivity of the MS to oxidation state, but the relationship is still not linear. To a first approximation, these two examples place bounds on the relationship between the MS and oxidation state for doubly valent Mn(III, IV) (hydr)oxides. Although beyond the scope of this study, subtle variations in MS and/or the relative amplitudes and shapes of the multiplets due to variations in bonding environments might yield a more linear relationship (e.g., [45]).

Addition of only $10 \% \mathrm{Mn}(\mathrm{II})$ to the synthetic Na-birn Mn3s spectra, considered in some cases to be below the detection limit [38], lowers the average valence but, counter-intuitively, decreases the MS (Figure 9, bottom panel). Hence, the presence of even minor Mn(II) renders the use of MS for determining the average oxidation state of birnessites even more problematic. Notably, this issue can occur at a MS value that indicates a purely Mn(IV) phase (Figure 9, bottom panel). In summary, the non-linearity of this particular system, including the strong effect of minor concentrations of Mn(II), explains the lack of correlation between the MS and birnessite oxidation states. Moreover, although the plateau in MS manifested in Galakhov et al. [44] between 3.0+ and 3.3+ is consistent with independent information suggesting interesting chemistry and physics (see above), the present contribution indicates that XPS evidence alone is not sufficient to make such an assessment: Plateaus can be accentuated by innocuous factors such as small shifts in BE separation between $\mathrm{Mn}(\mathrm{III})$ and $\mathrm{Mn}(\mathrm{IV})$. Given sufficient signal to noise, modeling the Mn3s peak is both possible and the preferred method for characterizing the oxidation states of birnessites and similar phases. 


\section{Conclusions}

The parameters used to fit XPS spectra for a variety of birnessite samples (Table 1) were vetted over a broad range of multivalent Mn (hydr)oxides and appear to yield accurate results for average Mn oxidation states and concentrations of $\mathrm{Mn}(\mathrm{II}), \mathrm{Mn}(\mathrm{III})$, and $\mathrm{Mn}(\mathrm{IV})$. In contrast, serious doubt has been raised concerning the efficacy of using Mn3s MS values for determining average oxidation states for birnessite (and likely other multivalent Mn phases). Fitting Mn3s and $\mathrm{Mn} 3 p$ spectra yielded nearly identical results for average oxidation states as well as close agreement with respect to mole fractions of $\mathrm{Mn}(\mathrm{IV}), \mathrm{Mn}(\mathrm{III})$, and $\mathrm{Mn}(\mathrm{II})$. Oxidation states determined from $\mathrm{Mn} 2 p_{3 / 2}$ are strongly correlated to $\mathrm{Mn} 3 p$ and $\mathrm{Mn} 3 s$ but are systematically more reduced. The Mn3p results are consistent with stoichiometry determined by charge balancing cations in the interlayers of birnessites (and tunnels of romanechite); furthermore, the Mn $3 p$ peak shape appears insensitive over a broad range to changes in Mn bonding environment, in contrast to the $\mathrm{Mn} 2 p_{3 / 2}$ line. Consequently, the close correspondence between Mn $3 p$ and Mn $3 s$ oxidation state values validates fitting the $\mathrm{Mn} 3 s$ spectra for measuring oxidation states. Two hypotheses for the discrepancy between $\mathrm{Mn} 2 p_{3 / 2}$ and the other core lines are (1) the very near-surface, which is weighted more heavily in the $\mathrm{Mn} 2 p_{3 / 2}$ signal, is more reduced than the bulk; and (2) the $\mathrm{Mn} 2 p_{3 / 2}$ results are not accurate due to the documented sensitivity of the peak shape to differences in the Mn bonding environment. Given that angle-resolved XPS of compressed vitreous samples indicated that the near-surface is not significantly more reduced than the bulk, it appears likely that the $\mathrm{Mn} 2 p_{3 / 2}$ results are not accurate. Indeed, the high variability of the goodness of fit to the $\mathrm{Mn} 2 p_{3 / 2}$ line as a function of composition and structure is consistent with this conclusion. Accurate use of the $\mathrm{Mn} 2 p_{3 / 2}$ line may require fine-tuning fit parameters to the mineral/compound of interest (e.g., K-birnessite [48-50]). Variable incident beam energies available at light sources 
could further resolve this issue. An accurate determination of Mn oxidation states using the $\mathrm{Mn} 2 p_{3 / 2}$ line would be useful precisely because of its greater surface sensitivity, and because it is the most intense line and is not susceptible to potential interferences from some common cations such as $\mathrm{Mg}$ and $\mathrm{Zn}$ that can plague the lower energy Mn lines. Additionally, accurate oxidation state determinations with $\mathrm{Mn} 3 p(3 s)$ could be combined with the greater sensitivity of $\mathrm{Mn} 2 p$ data to the bonding environment to obtain a more complete description of Mn speciation.

\section{Acknowledgements}

ESI and SNK were supported by the PNNL managed Geosciences Research Program of the U.S. Department of Energy (DOE), Office of Basic Energy Sciences, Division of Chemical Sciences, Geosciences \& Biosciences. The research was performed in part using the Environmental Molecular Sciences Laboratory (EMSL), a national scientific user facility sponsored by the U.S. DOE's Office of Biological and Environmental Research and located at Pacific Northwest National Laboratory (PNNL). PNNL is operated for DOE by Battelle Memorial Institute under Contract\# DE-AC06-76RLO-1830. We also acknowledge support from NSF EAR11-47728. We thank Paul Bagus for comments on an earlier version of the manuscript and both Manjula Nandasiri and Ashleigh Schwarz for operating the XPS facility. Comments by two anonymous reviewers are greatly appreciated.

\section{References}

[1] J.E. Post, Proceedings of the National Academy of Sciences of the United States of America 96 (1999) 3447-3454.

[2] E. Paterson, D.R. Clark, J.D. Russell, R. Swaffield, Clay Minerals 21 (1986) 957-964.

[3] C.L. Lopano, P.J. Heaney, J.Z. Bandstra, J.E. Post, S.L. Brantley, Geochimica Et Cosmochimica Acta 75 (2011) 3973-3981.

[4] C.L. Lopano, P.J. Heaney, J.E. Post, American Mineralogist 94 (2009) 816-826. 
[5] C.L. Lopano, P.J. Heaney, J.E. Post, J. Hanson, S. Komarneni, American Mineralogist 92 (2007) 380-387.

[6] C.R. Fleeger, P.J. Heaney, J.E. Post, American Mineralogist 98 (2013) 671-679.

[7] C. Negra, D.S. Ross, A. Lanzirotti, Soil Science Society of America Journal 69 (2005) 87-95.

[8] D. Fandeur, F. Juillot, G. Morin, L. Olivi, A. Cognigni, S.M. Webb, J.P. Ambrosi, E. Fritsch, F. Guyot, G.E. Brown, Environmental Science \& Technology 43 (2009) 7384-7390.

[9] X.H. Feng, L.M. Zhai, W.F. Tan, F. Liu, J.Z. He, Environmental Pollution 147 (2007) 366-373.

[10] L.E. Eary, D. Rai, Environmental Science \& Technology 21 (1987) 1187-1193.

[11] H. Guha, J.E. Saiers, S. Brooks, P. Jardine, K. Jayachandran, Journal of Contaminant Hydrology 49 (2001) 311-334.

[12] R.M. Weaver, M.F. Hochella, American Mineralogist 88 (2003) 2016-2027.

[13] M.W. Rophael, S.N. Boulis, Surface Technology 16 (1982) 243-248.

[14] X.H. Feng, L.M. Zhai, W.F. Tan, W. Zhao, F. Liu, J.Z. He, Journal of Colloid and Interface Science 298 (2006) 258-266.

[15] A. Manceau, L. Charlet, Journal of Colloid and Interface Science 148 (1992) 425-442.

[16] S.E. Fendorf, M. Fendorf, D.L. Sparks, R. Gronsky, Journal of Colloid and Interface Science 153 (1992) 37-54.

[17] S.E. Fendorf, R.J. Zasoski, Environmental Science \& Technology 26 (1992) 79-85.

[18] P.S. Nico, R.J. Zasoski, Environmental Science \& Technology 34 (2000) 3363-3367.

[19] S. Fujimori, Y. Saito, N. Sato, T. Komatsubara, S. Suzuki, S. Sato, T. Ishii, Solid State Communications 105 (1998) 185-188.

[20] G. Landrot, M. Ginder-Vogel, K. Livi, J.P. Fitts, D.L. Sparks, Environmental Science \& Technology 46 (2012) 11594-11600.

[21] G. Landrot, M. Ginder-Vogel, K. Livi, J.P. Fitts, D.L. Sparks, Environmental Science \& Technology 46 (2012) 11601-11609.

[22] J.E. Post, D.R. Veblen, American Mineralogist 75 (1990) 477-489.

[23] V.A. Drits, E. Silvester, A.I. Gorshkov, A. Manceau, American Mineralogist 82 (1997) 946-961.

[24] E. Silvester, A. Manceau, V.A. Drits, American Mineralogist 82 (1997) 962-978.

[25] B. Lanson, V.A. Drits, E. Silvester, A. Manceau, American Mineralogist 85 (2000) 826-838.

[26] J.E. Post, P.J. Heaney, J. Hanson, Powder Diffraction 17 (2002) 218-221.

[27] P. Kurz, M. Wiechen, Nachrichten Aus Der Chemie 60 (2012) 24-28.

[28] M. Wiechen, H.-M. Berends, P. Kurz, Dalton Transactions 41 (2012) 21-31.

[29] M. Wiechen, I. Zaharieva, H. Dau, P. Kurz, Chemical Science 3 (2012) 2330-2339.

[30] G. Elmaci, C.E. Frey, P. Kurz, B. Zumreoglu-Karan, Inorganic Chemistry 54 (2015) 2734-2741.

[31] F.F. Marafatto, M.L. Strader, J. Gonzalez-Holguera, A. Schwartzberg, B. Gilbert, J. Pena, Proceedings of the National Academy of Sciences of the United States of America 112 (2015) 4600-4605.

[32] I.G. McKendry, S.K. Kondaveeti, S.L. Shumlas, D.R. Strongin, M.J. Zdilla, Dalton Transactions 44 (2015) 12981-12984.

[33] A. Manceau, A.I. Gorshkov, V.A. Drits, American Mineralogist 77 (1992) 1133-1143.

[34] E. Chalmin, F. Farges, G. Brown, Contributions to Mineralogy and Petrology 157 (2009) 111-126.

[35] A. Manceau, M.A. Marcus, S. Grangeon, American Mineralogist 97 (2012) 816-827.

[36] I.N. Demchenko, K. Lawniczak-Jablonska, T. Tyliszczak, N.R. Birkner, W.C. Stolte, M. Chernyshova, O. Hemmers, Journal of Electron Spectroscopy and Related Phenomena 171 (2009) 24-29.

[37] Y.S. Jun, S.T. Martin, Environmental Science \& Technology 37 (2003) 2363-2370.

[38] J. Junta, M.F. Hochella, Geochimica Et Cosmochimica Acta 58 (1994) 4985-4999.

[39] A.J. Nelson, J.G. Reynolds, J.W. Roos, Journal of Vacuum Science \& Technology a-Vacuum Surfaces and Films 18 (2000) 1072-1076.

[40] P.S. Bagus, R. Broer, E.S. Ilton, Chemical Physics Letters 394 (2004) 150-154. 
[41] P.S. Bagus, R. Broer, E.S. Ilton, Journal of Electron Spectroscopy and Related Phenomena 165 (2008) 46-49.

[42] L. Sangaletti, P.S. Bagus, F. Parmigiani, Physical Review B 62 (2000) R7695-R7698.

[43] P.S. Bagus, A.J. Freeman, F. Sasaki, Physical Review Letters 30 (1973) 850-853.

[44] V.R. Galakhov, M. Demeter, S. Bartkowski, M. Neumann, N.A. Ovechkina, E.Z. Kurmaev, N.I. Logachevskaya, Y.M. Mukovskii, J. Mitchell, D.L. Ederer, Physical Review B 65 (2002).

[45] A.T. Kozakov, A.G. Kochur, K.A. Googlev, A.V. Nikolskii, V.I. Torgashev, V.G. Trotsenko, A.A. Bush, Journal of Alloys and Compounds 647 (2015) 947-955.

[46] J.W. Murray, J.G. Dillard, R. Giovanoli, H. Moers, W. Stumm, Geochimica Et Cosmochimica Acta 49 (1985) 463-470.

[47] S. Ardizzone, C.L. Bianchi, D. Tirelli, Colloids and Surfaces a-Physicochemical and Engineering Aspects 134 (1998) 305-312.

[48] H.W. Nesbitt, D. Banerjee, American Mineralogist 83 (1998) 305-315.

[49] D. Banerjee, H.W. Nesbitt, Geochimica Et Cosmochimica Acta 63 (1999) 3025-3038.

[50] D. Banerjee, H.W. Nesbitt, Geochimica Et Cosmochimica Acta 63 (1999) 1671-1687.

[51] E.S. Ilton, T.C. Droubay, A.M. Chaka, L. Kovarik, T. Varga, B.W. Arey, S.N. Kerisit, Surface Science 632 (2015) 185-194.

[52] J.M. Cerrato, M.F. Hochella, Jr., W.R. Knocke, A.M. Dietrich, T.F. Cromer, Environmental Science \& Technology 44 (2010) 5881-5886.

[53] J.M. Cerrato, W.R. Knocke, M.F. Hochella, Jr., A.M. Dietrich, A. Jones, T.F. Cromer, Environmental Science \& Technology 45 (2011) 10068-10074.

[54] R.P. Gupta, S.K. Sen, Physical Review B 10 (1974) 71-77.

[55] R.P. Gupta, S.K. Sen, Physical Review B 12 (1975) 15-19.

[56] D.C. Golden, C.C. Chen, J.B. Dixon, Science 231 (1986) 717-719.

[57] M.C. Biesinger, B.P. Payne, A.P. Grosvenor, L.W.M. Lau, A.R. Gerson, R.S. Smart, Applied Surface Science 257 (2011) 2717-2730.

[58] P.S. Bagus, E.S. Ilton, Physical Review B 73 (2006).

[59] J.E. Post, P.J. Heaney, A. Ertl, Powder Diffraction 23 (2008) 10-14.

[60] P.S. Bagus, E.S. Ilton, C.J. Nelin, Surface Science Reports 68 (2013) 273-304.

[61] M.C. Biesinger, B.P. Payne, L.W.M. Lau, A. Gerson, R.S.C. Smart, Surface and Interface Analysis 41 (2009) 324-332.

[62] S. Turner, J.E. Post, American Mineralogist 73 (1988) 1155-1161.

[63] J.E. Post, R.B. Vondreele, P.R. Buseck, Acta Crystallographica Section B-Structural Science 38 (1982) 1056-1065.

[64] S.S. Tripathy, S.B. Kanungo, S.K. Mishra, Journal of Colloid and Interface Science 241 (2001) 112-

119.

[65] L.Z. Zhao, V. Young, Journal of Electron Spectroscopy and Related Phenomena 34 (1984) 45-54. 


\section{Table 1. Fit parameters from standards ${ }^{a}$}

\begin{tabular}{|c|c|c|c|c|c|c|c|c|}
\hline Mn3p & P1 & P2 & P3 & $\mathrm{P} 4$ & P5 & & & \\
\hline \multicolumn{9}{|l|}{ Ranciete-Mn(IV) } \\
\hline I (rel) & 1.00 & 0.258 & 0.095 & 0.052 & 0.010 & & & \\
\hline $\mathrm{BE}(\mathrm{eV})$ & 49.94 & 51.29 & 52.68 & 54.08 & 55.56 & & & \\
\hline FWHM $(\mathrm{eV})$ & 1.63 & 1.63 & 1.63 & 1.63 & 1.63 & & & \\
\hline $\begin{array}{c}\mathrm{G} / \mathrm{L} \\
\text { Manganite-Mn(I }\end{array}$ & 30 & 30 & 30 & 30 & 30 & & & \\
\hline I (rel) & 1.00 & 0.426 & 0.233 & 0.097 & 0.025 & & & \\
\hline $\mathrm{BE}(\mathrm{eV})$ & 48.79 & 49.92 & 51.11 & 52.52 & 46.57 & & & \\
\hline FWHM $(\mathrm{eV})$ & 1.47 & 1.47 & 1.47 & 1.47 & 1.26 & & & \\
\hline $\begin{array}{c}\mathrm{G} / \mathrm{L} \\
\mathrm{MnO}-\mathrm{Mn}(\mathrm{II})\end{array}$ & 30 & 30 & 30 & 30 & 30 & & & \\
\hline I (rel) & 1.00 & 0.322 & 0.393 & & & & & \\
\hline $\mathrm{BE}(\mathrm{eV})$ & 47.46 & 48.16 & 49.59 & & & & & \\
\hline FWHM $(\mathrm{eV})$ & 1.16 & 0.96 & 2.05 & & & & & \\
\hline G/L & 30 & 30 & 30 & & & & & \\
\hline Mn3s & P1 & P2 & P3 & P4 & P5 & & $1 S(e V)$ & \\
\hline \multicolumn{9}{|l|}{ Pyrolusite-Mn(IV) } \\
\hline I (rel) & 1.00 & 0.557 & 0.113 & & & & 4.4 & \\
\hline$B E(e V)$ & 85.34 & 89.80 & 94.49 & & & & & \\
\hline FWHM $(\mathrm{eV})$ & 2.44 & 3.46 & 6.49 & & & & & \\
\hline$G / L$ & 80 & 80 & 30 & & & & & \\
\hline \multicolumn{9}{|c|}{ Manganite-Mn(III) } \\
\hline $\mathrm{I}(\mathrm{rel})$ & 1.00 & 0.466 & 0.701 & 0.159 & 0.046 & & 5.4 & \\
\hline $\mathrm{BE}(\mathrm{eV})$ & 83.92 & 84.79 & 89.45 & 92.22 & 94.49 & & & \\
\hline FWHM $(\mathrm{eV})$ & 2.33 & 3.59 & 2.81 & 3.60 & 2.25 & & & \\
\hline $\begin{array}{c}\mathrm{G} / \mathrm{L} \\
\mathrm{MnO}-\mathrm{Mn}(\mathrm{II})\end{array}$ & 70 & 70 & 70 & 70 & 70 & & & \\
\hline $\mathrm{I}(\mathrm{rel})$ & 1.00 & 0.232 & 0.262 & 0.543 & 0.042 & & 6.1 & \\
\hline $\mathrm{BE}(\mathrm{eV})$ & 82.21 & 83.71 & 88.26 & 88.69 & 94.67 & & & \\
\hline FWHM $(\mathrm{eV})$ & 2.22 & 4.42 & 1.46 & 3.51 & 2.43 & & & \\
\hline $\mathrm{G} / \mathrm{L}$ & 80 & 80 & 80 & 80 & 80 & & & \\
\hline Mn2p & $\mathrm{P1}$ & P2 & P3 & P4 & P5 & P6 & $\mathrm{P7}$ & P8 \\
\hline \multicolumn{9}{|l|}{ Ranciete-Mn(IV) } \\
\hline $\mathrm{I}(\mathrm{rel})$ & 1.00 & 0.534 & 0.496 & 0.277 & 0.167 & 0.087 & 0.036 & $0.013^{*}$ \\
\hline $\mathrm{BE}(\mathrm{eV})$ & 642.03 & 642.81 & 643.40 & 644.10 & 644.88 & 645.79 & 646.88 & 647.10 \\
\hline FWHM $(\mathrm{eV})$ & 1.02 & 1.02 & 1.02 & 1.02 & 1.02 & 1.02 & 1.02 & 1.02 \\
\hline $\begin{array}{c}\mathrm{G} / \mathrm{L} \\
\text { Manganite-Mn(I }\end{array}$ & 50 & 50 & 50 & 50 & 50 & 50 & 50 & 50 \\
\hline $\mathrm{I}(\mathrm{rel})$ & 0.995 & 1.00 & 0.798 & 0.618 & 0.326 & 0.175 & 0.073 & $0.036^{*}$ \\
\hline $\mathrm{BE}(\mathrm{eV})$ & 640.78 & 641.57 & 642.25 & 643.01 & 643.83 & 644.67 & 645.69 & 638.98 \\
\hline FWHM $(\mathrm{eV})$ & 1.17 & 1.17 & 1.17 & 1.17 & 1.17 & 1.17 & 1.17 & 1.49 \\
\hline $\begin{array}{c}\mathrm{G} / \mathrm{L} \\
\mathrm{MnO}-\mathrm{Mn}(\mathrm{II})\end{array}$ & 50 & 50 & 50 & 50 & 50 & 50 & 50 & 50 \\
\hline I (rel) & 1.00 & 0.705 & 0.507 & 0.356 & 0.164 & 0.080 & 0.320 & $0.039^{*}$ \\
\hline $\mathrm{BE}(\mathrm{eV})$ & 639.28 & 640.32 & 641.08 & 641.96 & 643.04 & 644.13 & 646.16 & 637.63 \\
\hline FWHM $(\mathrm{eV})$ & 1.27 & 1.27 & 1.27 & 1.27 & 1.27 & 1.67 & 2.69 & 1.47 \\
\hline $\mathrm{G} / \mathrm{L}$ & 30 & 30 & 30 & 30 & 30 & 30 & 30 & 30 \\
\hline
\end{tabular}

${ }^{a}$ Vamas files for CasaXPS with representative fits will be provided upon request.

${ }^{*}$ We have found that including small peaks at the high and low BE tails helps. 


\section{Table 2. Fit results for birnessite samples}

\begin{tabular}{|c|c|c|c|c|c|}
\hline Sample & $\% \mathrm{Mn}(\mathrm{IV})$ & \%Mn(III) & $\% M n(I I)$ & <average> & rsd \\
\hline \multicolumn{6}{|c|}{ Hex-birn-pH7 } \\
\hline$M n 3 p$ & 0.63 & 0.22 & 0.15 & $3.47+$ & 1.10 \\
\hline Mn3s & 0.69 & 0.13 & 0.19 & $3.50+$ & 1.08 \\
\hline$M n 3 s^{a}$ & 0.65 & 0.16 & 0.19 & $3.46+$ & 1.08 \\
\hline $\mathrm{Mn} 2 \mathrm{p}$ & 0.53 & 0.23 & 0.24 & $3.30+$ & 1.48 \\
\hline \multicolumn{6}{|c|}{ Hex-birn-pH2 } \\
\hline$M n 3 p$ & 0.68 & 0.22 & 0.10 & $3.58+$ & 1.26 \\
\hline Mn3s & 0.68 & 0.20 & 0.12 & $3.55+$ & 1.16 \\
\hline $\operatorname{Mn} 3 s^{a}$ & 0.64 & 0.23 & 0.12 & $3.52+$ & 1.16 \\
\hline$M n 2 p$ & 0.54 & 0.29 & 0.17 & $3.38+$ & 1.33 \\
\hline \multicolumn{6}{|l|}{ Tri-K-birn } \\
\hline $\mathrm{Mn3p}$ & 0.58 & 0.38 & 0.04 & $3.54+$ & 1.65 \\
\hline Mn3s & 0.60 & 0.35 & 0.06 & $3.54+$ & 1.27 \\
\hline$M n 3 s^{a}$ & 0.57 & 0.38 & 0.06 & $3.51+$ & 1.27 \\
\hline $\mathrm{Mn} 2 \mathrm{p}$ & 0.47 & 0.45 & 0.08 & $3.39+$ & 4.34 \\
\hline \multicolumn{6}{|c|}{ Tri-Na-birn } \\
\hline Mn3p & 0.60 & 0.38 & 0.02 & $3.57+$ & 1.71 \\
\hline Mn3s & 0.59 & 0.40 & 0.01 & $3.58+$ & 1.18 \\
\hline$M n 3 s^{a}$ & 0.56 & 0.43 & 0.01 & $3.55+$ & 1.18 \\
\hline$M n 2 p$ & 0.45 & 0.50 & 0.05 & $3.40+$ & 3.24 \\
\hline \multicolumn{6}{|c|}{ Tri-Ca-birn } \\
\hline$M n 3 p$ & 0.64 & 0.29 & 0.07 & $3.58+$ & 1.25 \\
\hline Mn3s & 0.67 & 0.25 & 0.08 & $3.59+$ & 1.09 \\
\hline $\operatorname{Mn} 3 s^{a}$ & 0.64 & 0.29 & 0.08 & $3.56+$ & 1.08 \\
\hline $\mathrm{Mn} 2 \mathrm{p}$ & 0.52 & 0.37 & 0.10 & $3.42+$ & 2.15 \\
\hline \multicolumn{6}{|c|}{ Tri-Ba-birn } \\
\hline $\mathrm{Mn} 3 p$ & 0.56 & 0.40 & 0.04 & $3.52+$ & 1.39 \\
\hline$M n 3 s^{b}$ & nd & nd & nd & nd & nd \\
\hline$M n 2 p$ & 0.43 & 0.50 & 0.07 & $3.37+$ & 2.44 \\
\hline
\end{tabular}

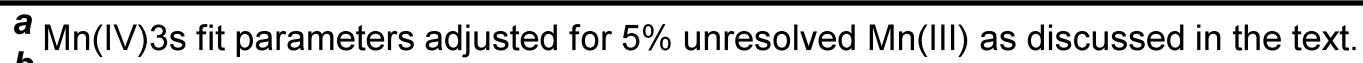

$\boldsymbol{b}_{\text {Not determined (nd): Ba interfered with the Mn3s line. }}$

Uncertainties determined by varying background positions for $\mathrm{Mn3s}(\mathrm{Mn3p})$ yield ranges in absolute mole fraction on the order of "0.02(0.01) for $\mathrm{Mn}(\mathrm{IV})$ and $\mathrm{Mn}(\mathrm{III})$, "0.01(0.005) for $\mathrm{Mn}(\mathrm{II})$, and " $0.02(0.01)$ for average oxidation states The position of the high $\mathrm{BE}$ background for the $\mathrm{Mn} 2 \mathrm{p}_{3 / 2}$ line was more subjective (see text). Due to long acquisition times, particularly for Mn3s and Mn3p, it was only feasible to take two spectra per energy level per sample. The variation in results between two spectra taken on the same sample was less than the variation due to the uncertainty in the background positions. 


\section{Figure Captions}

Figure 1. Illustration of fit parameters for $\mathrm{MnO}$ (top three panels), $\mathrm{MnOOH}$ (middle three panels) and $\mathrm{MnO}_{2}$ (bottom three panels). *Best fit to rancieite. **Best fit to UV-ozoned pyrolusite.

Figure 2. $\mathrm{MnO}$ best fit using $\mathrm{MnCO}_{3}$ where the individual component peaks are not shown for clarity. The top, middle and bottom panels are for $\operatorname{Mn} 3 p, \operatorname{Mn} 2 p$, and $\mathrm{Mn} 3 s$ respectively.

Figure 3. Bixbyite $\left(\mathrm{Mn}_{2} \mathrm{O}_{3}\right)$ best fit using fit parameters for manganite $(\mathrm{MnOOH})$. The left panel is $\mathrm{Mn} 3 p$ and the right panel is $\mathrm{Mn} 2 p_{3 / 2}$.

Figure 4. Pyrolusite $\left(\mathrm{MnO}_{2}\right)$ best fit using $\mathrm{Mn}(\mathrm{IV})$ parameters for rancieite $\left(\mathrm{MnO}_{2}\right)$ and $\mathrm{Mn}(\mathrm{III})$ parameters from manganite $(\mathrm{MnOOH})$. The left panel is $\mathrm{Mn} 3 p$ and the right panel is $\mathrm{Mn} 2 p_{3 / 2}$.

Figure 5. Hausmannite $\left(\mathrm{Mn}_{3} \mathrm{O}_{4}\right)$ best fit using $\mathrm{Mn}(\mathrm{III})$ parameters for manganite $(\mathrm{MnOOH})$ and $\mathrm{Mn}(\mathrm{II})$ parameters for $\mathrm{MnO}$. The top panel is $\mathrm{Mn} 2 p_{3 / 2}$ and the right panel is $\mathrm{Mn} 3 p$.

Figure 6. Hexagonal pH 7 birnessite best fit using $\mathrm{Mn}(\mathrm{II}), \mathrm{Mn}(\mathrm{III})$, and $\mathrm{Mn}(\mathrm{IV})$ parameters derived from $\mathrm{MnO}, \mathrm{MnOOH}$ (manganite), and $\mathrm{MnO}_{2}$ (rancieite), respectively. For clarity only the composite peak envelopes for the different oxidation states are shown. The insets are the background subtracted composite peaks for the three different oxidation states. 
Figure 7. Correlations between the average oxidations states of birnessites samples determined by fitting the Mn $3 s, \operatorname{Mn} 3 p$ and Mn2p lines. The open and closed circles are for Mn3s:Mn3p and Mn3s:Mn2p correlations, respectively. The inset shows the Mn3p:Mn2p correlation. The uncertainties are explained in the footnote to Table 2. The heavy dashed line marks the 1:1 correlation. The light dashed line is a guide to the eye.

Figure 8. Correlations between the mole fractions of individual oxidations states of birnessite samples determined by fitting the $\mathrm{Mn} 3 s, \mathrm{Mn} 3 p$ and $\mathrm{Mn} 2 p_{3 / 2}$ lines. The top, middle and bottom panels are for $\mathrm{Mn}(\mathrm{IV}), \mathrm{Mn}(\mathrm{III})$, and $\mathrm{Mn}(\mathrm{II})$, respectively. Open and closed circles record Mn3s:Mn3p and Mn3s:Mn2p $p_{3 / 2}$ correlations, respectively. The uncertainties are explained in the footnote to Table 2. The heavy dashed line marks the 1:1 correlation. The light dashed line is a guide to the eye.

Figure 9. The correlation between multiplet splitting of the $\mathrm{Mn} 3 s$ line and the average oxidation state from fitting the Mn3s line. Top panel for birnessite samples (closed symbols) and $\mathrm{Mn}$ (III) and $\mathrm{Mn}(\mathrm{IV})$ standards (open symbols). Inset is discussed in the text. Bottom panel for synthetic spectra. 

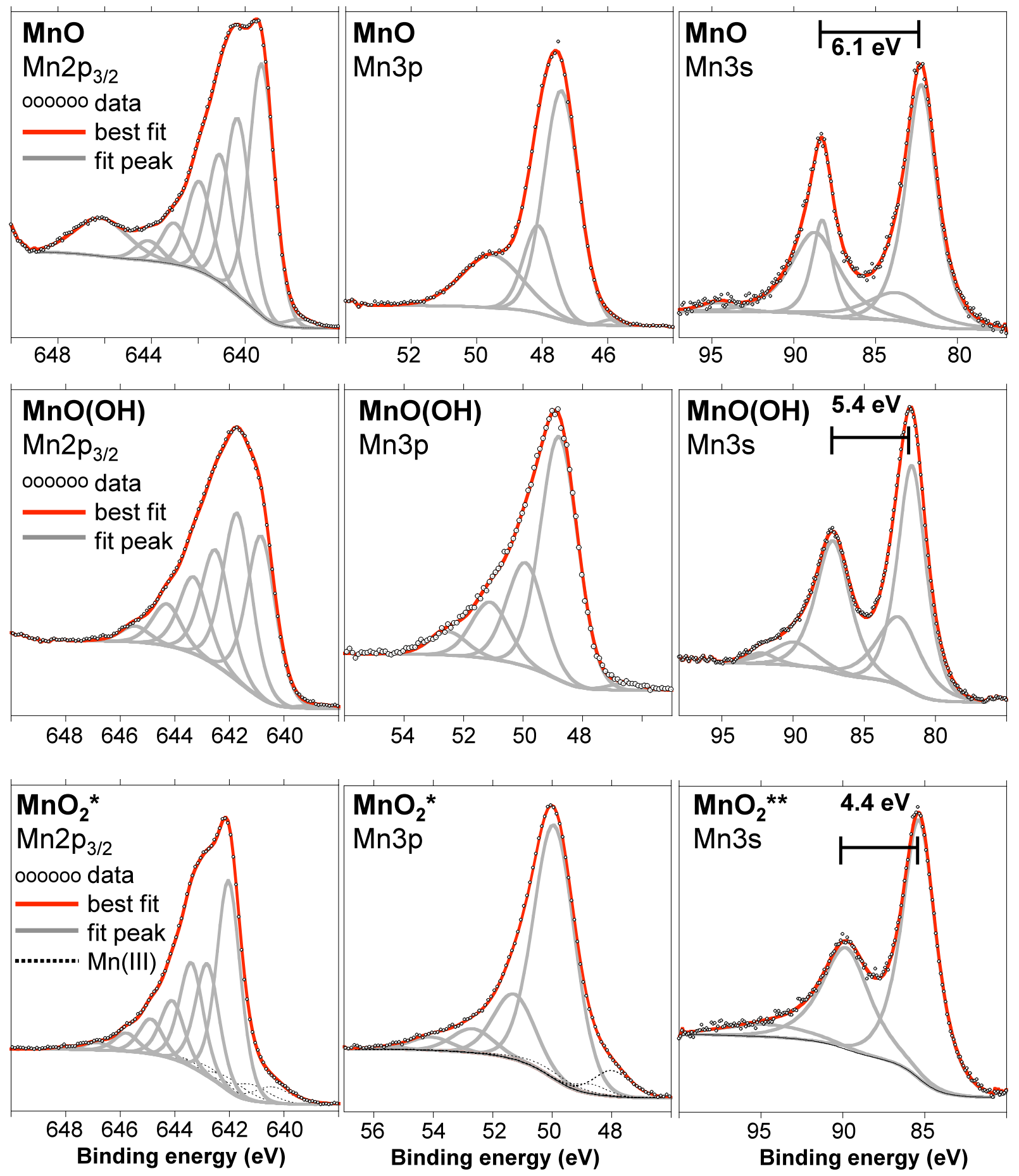

Figure 1. 

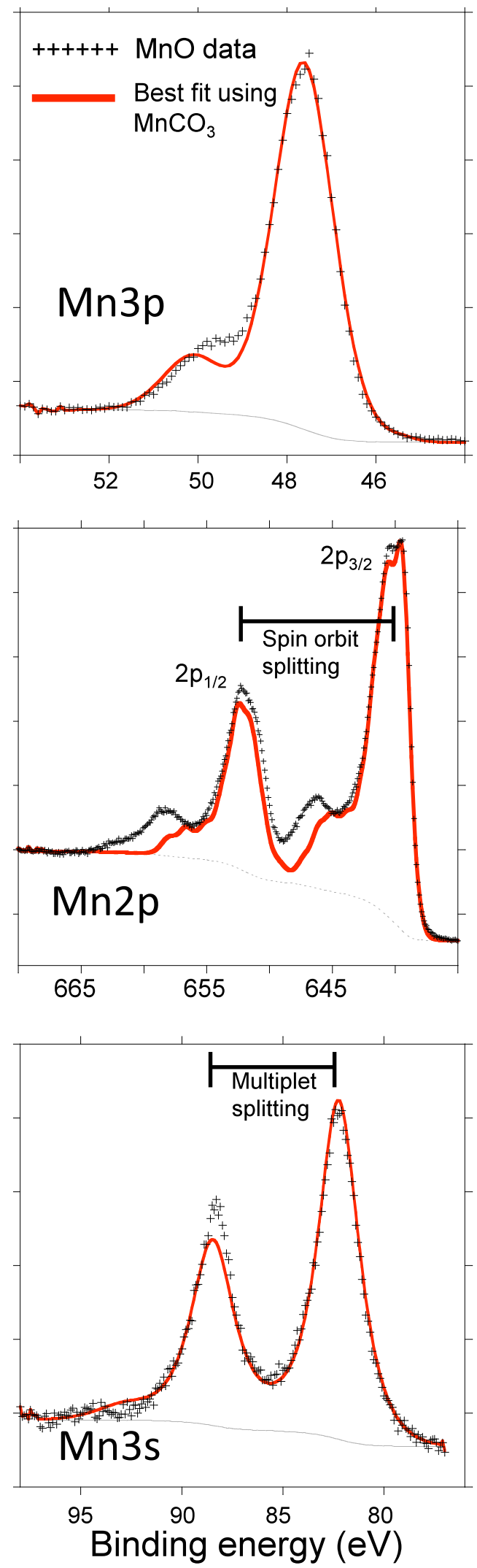

Figure 2 

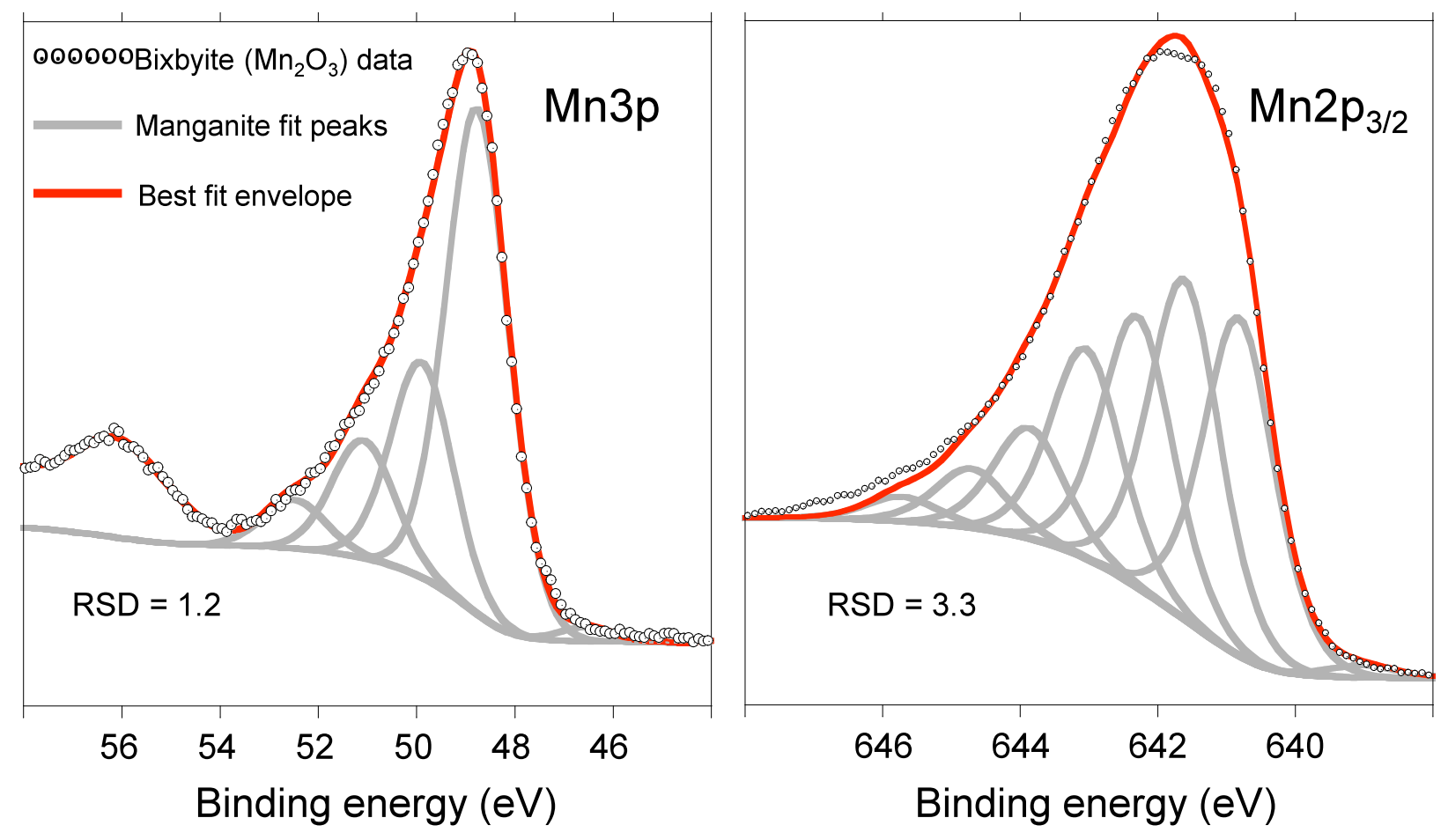

Figure 3 

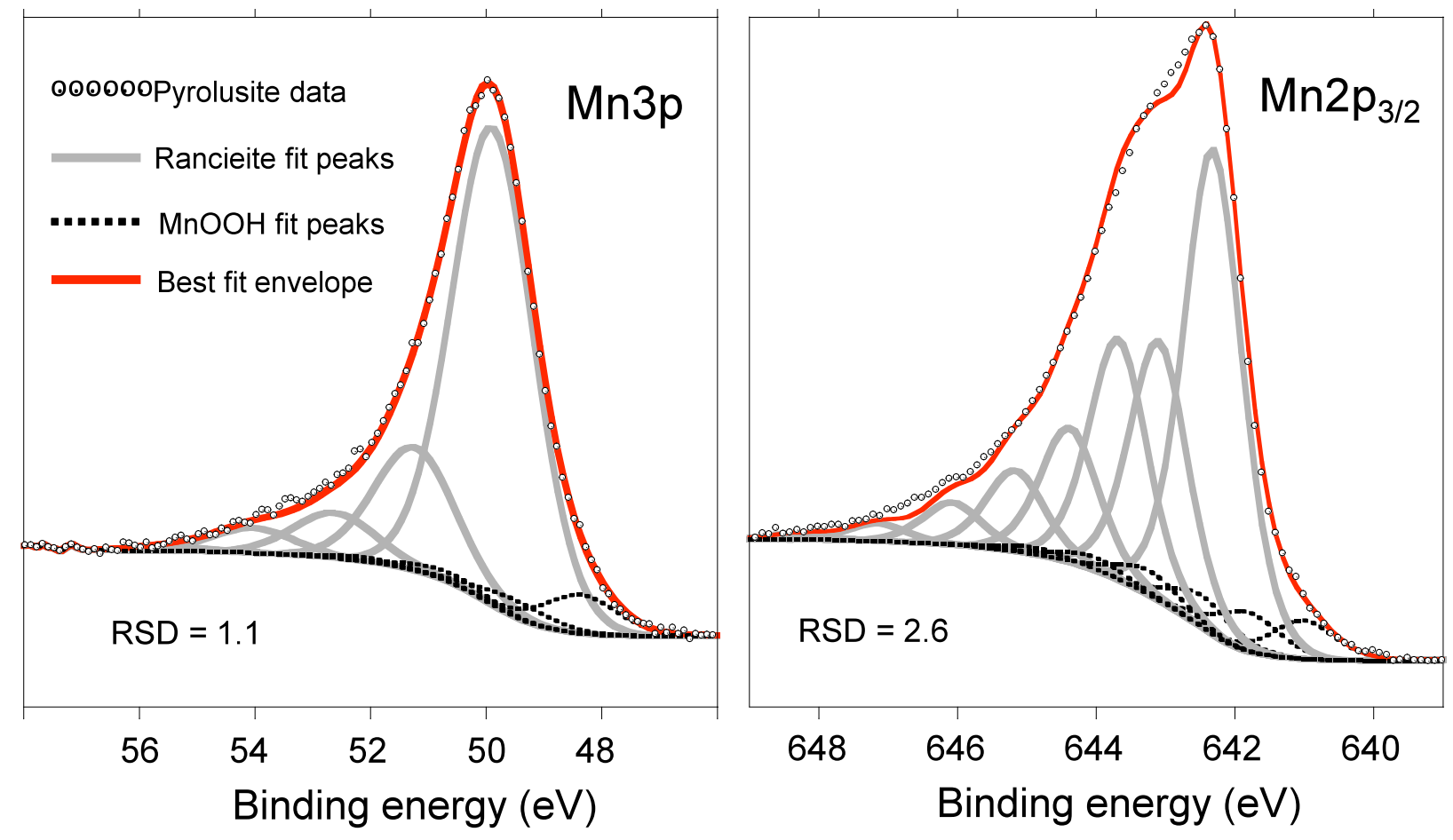

Figure 4 

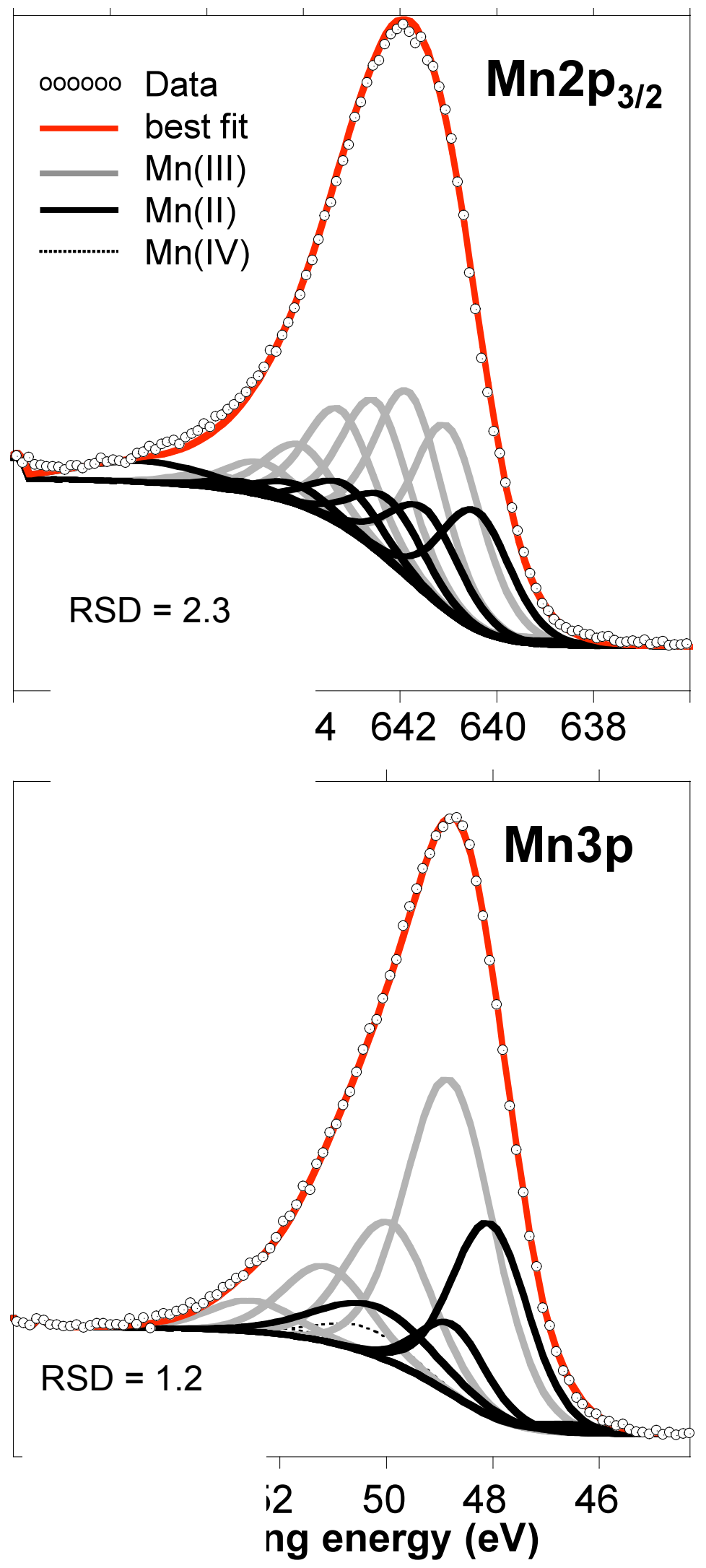

Figure 5 

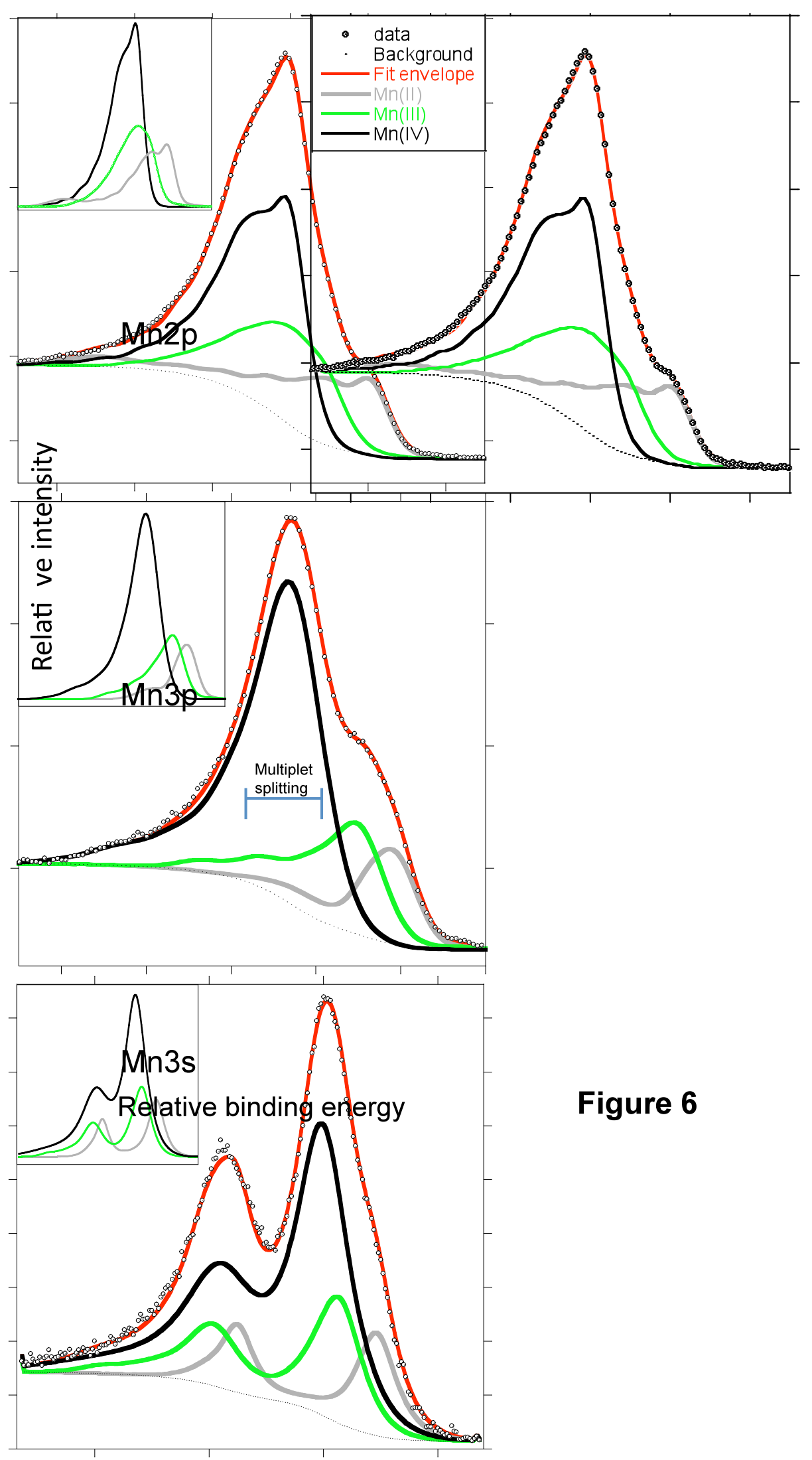

Figure 6

38 


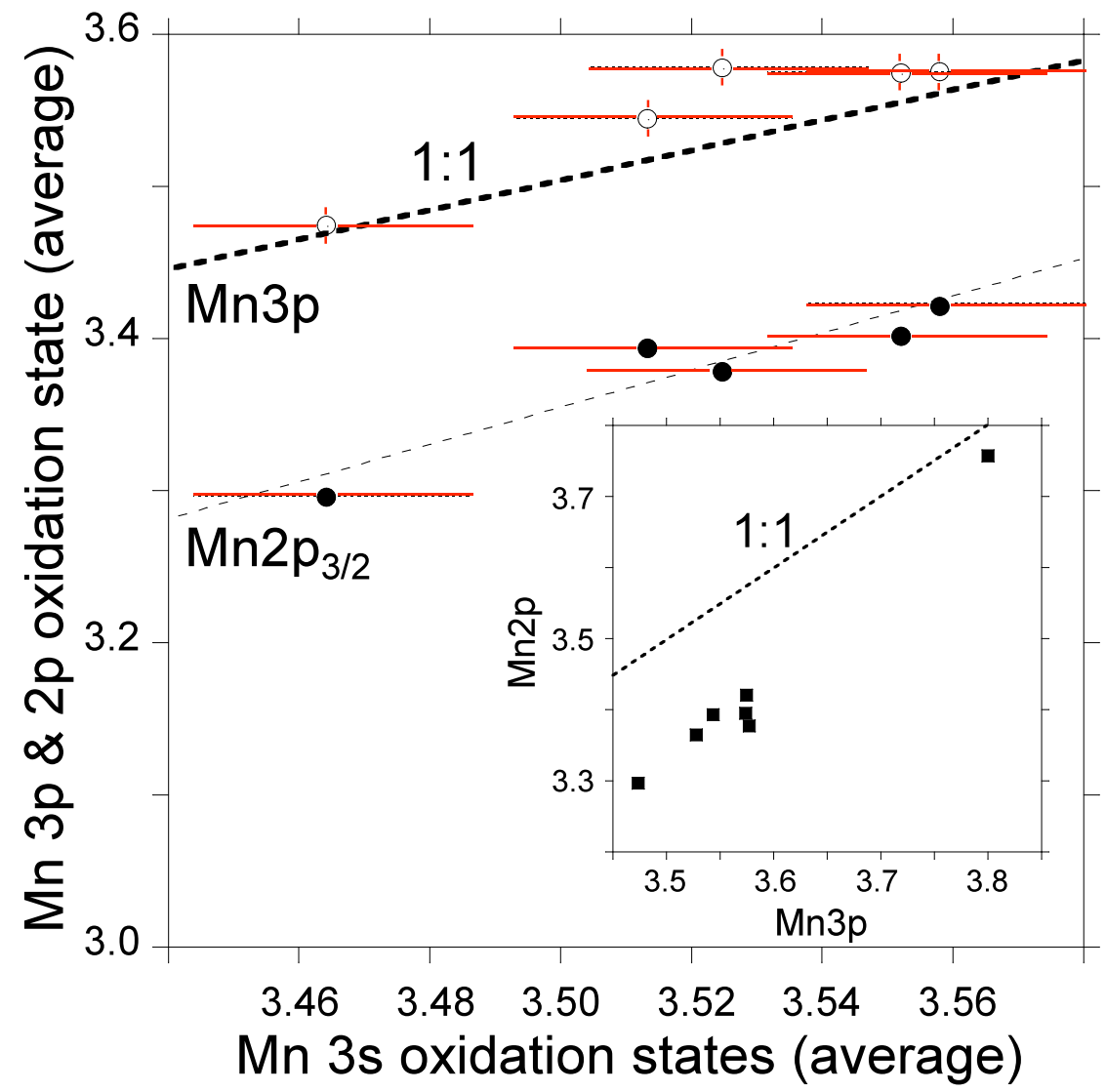

Figure 7 

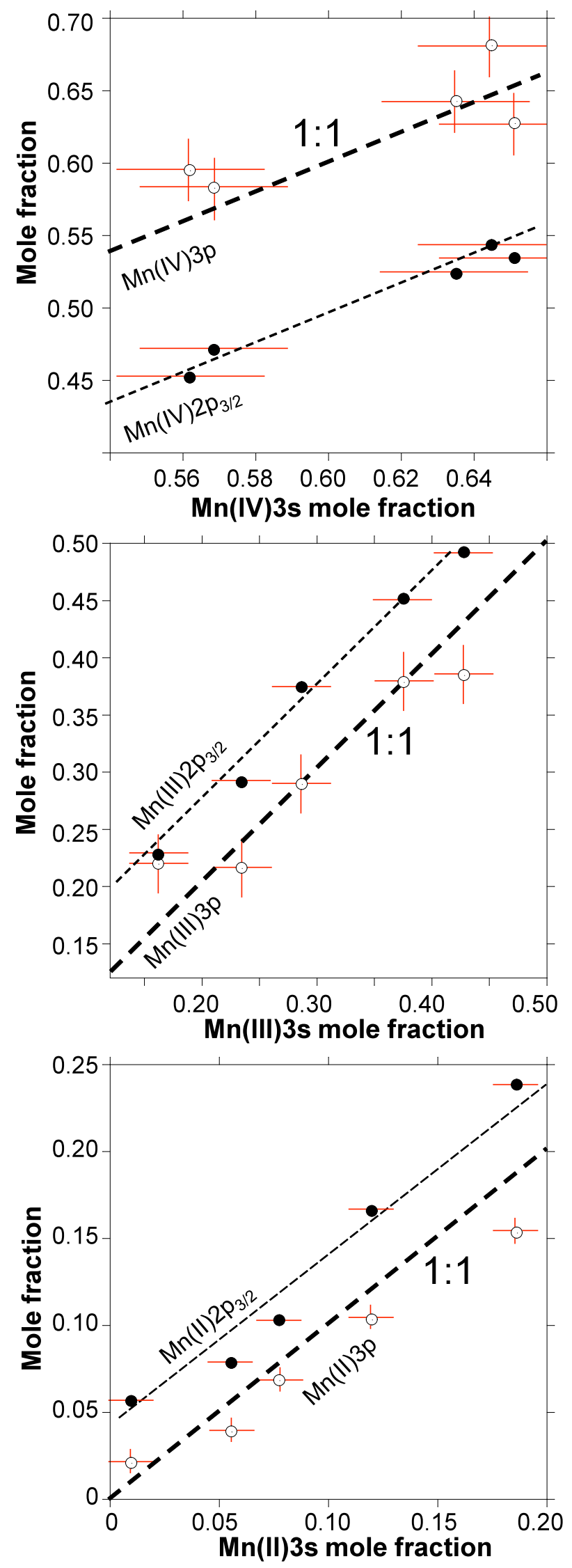

Figure 8 


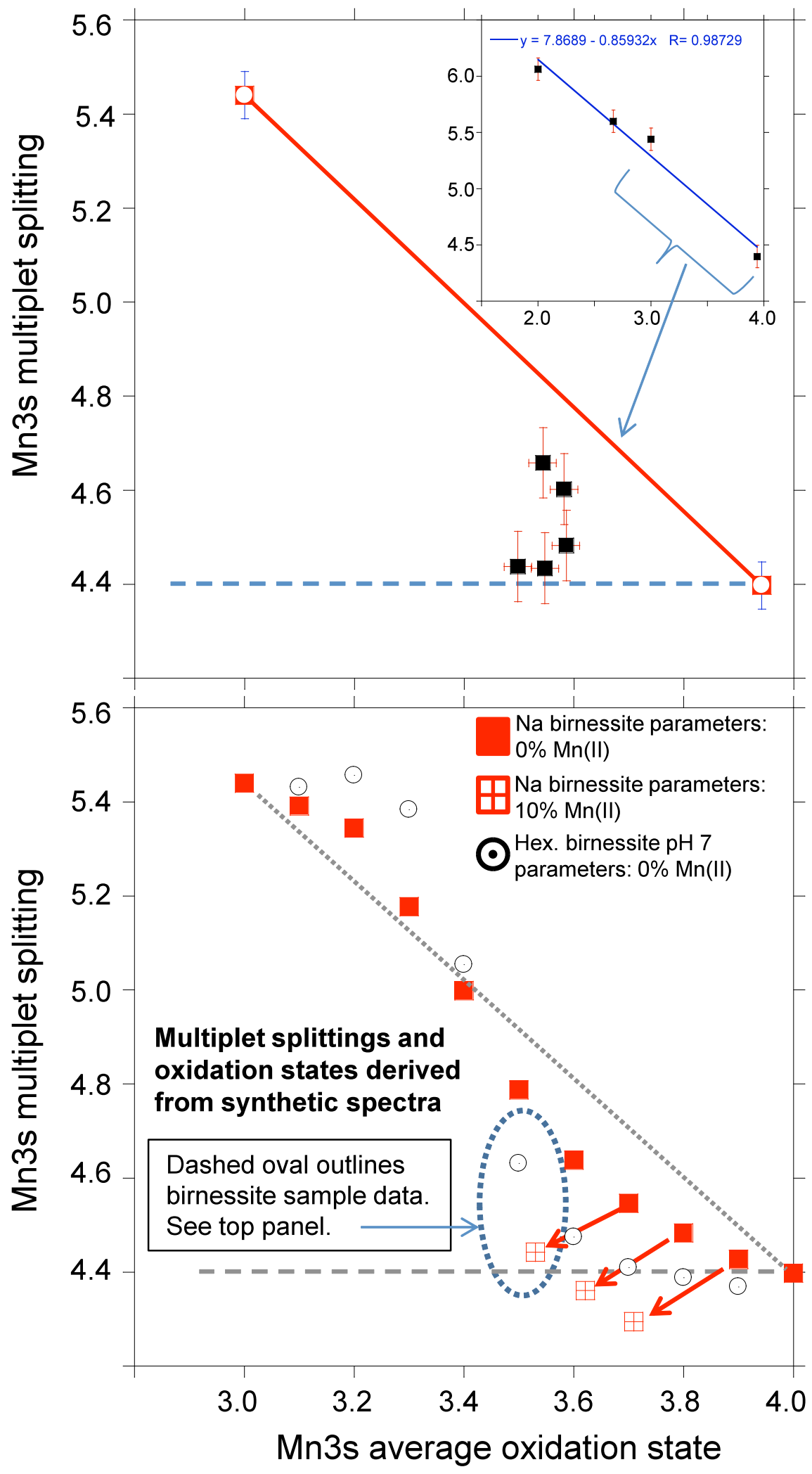

Figure 9 